\title{
Optimal Control of Centralized Thermoelectric Generation System under Nonuniform Temperature Distribution Using Barnacles Mating Optimization Algorithm
}

\author{
Mirza Imran Tariq ${ }^{1}$, Majad Mansoor ${ }^{2}$, Adeel Feroz Mirza ${ }^{2}$, Nouman Mujeeb Khan ${ }^{1}$, Muhammad Hamza Zafar ${ }^{1, *}$, \\ Abbas Z. Kouzani ${ }^{3}$ and M. A. Parvez Mahmud ${ }^{3}$ (iD \\ 1 Department of Electrical Engineering, Capital University of Science and Technology, Islamabad 44000, \\ Pakistan; mit.kashi@gmail.com (M.I.T.); naumanmujeebk@gmail.com (N.M.K.) \\ 2 Department of Automation China, University of Science and Technology of China, Hefei 230052, China; \\ majad@mail.ustc.edu.cn (M.M.); adeelmirza@mail.ustc.edu.cn (A.F.M.) \\ 3 School of Engineering, Deakin University, Geelong 3216, Australia; abbas.kouzani@deakin.edu.au (A.Z.K.); \\ m.a.mahmud@deakin.edu.au (M.A.P.M.) \\ * Correspondence: hamzauetms@gmail.com
}

Citation: Tariq, M.I.; Mansoor, M.; Feroz Mirza, A.; Khan, N.M.; Zafar, M.H.; Z. Kouzani, A.; Mahmud,

M.A.P. Optimal Control of

Centralized Thermoelectric

Generation System under

Nonuniform Temperature

Distribution Using Barnacles Mating Optimization Algorithm. Electronics 2021, 10, 2839. https://doi.org/ 10.3390/electronics10222839

Academic Editor: Davide Astolfi

Received: 1 November 2021

Accepted: 16 November 2021

Published: 18 November 2021

Publisher's Note: MDPI stays neutral with regard to jurisdictional claims in published maps and institutional affiliations.

Copyright: (c) 2021 by the authors. Licensee MDPI, Basel, Switzerland. This article is an open access article distributed under the terms and conditions of the Creative Commons Attribution (CC BY) license (https:/ / creativecommons.org/licenses/by/ $4.0 /)$.

\begin{abstract}
The need for renewable energy resources is ever-increasing due to the concern for environmental issues associated with fossil fuels. Low-cost high-power-density manufacturing techniques for the thermoelectric generators (TEG) have added to the technoeconomic feasibility of the TEG systems as an effective power generation system in heat recovery, cooling, electricity, and engineefficiency applications. The environment-dependent factors such as the nonuniform distribution of heat, damage to the heat-transfer coating between sinks and sources, and mechanical faults create nonuniform current generation and impedance mismatch causing power loss. As a solution to this nonlinear multisolution problem, an improved MPPT control is presented, which utilizes the improvised barnacle mating optimization (BMO). The case studies are formulated to gauge the performance of the proposed BMP MPPT control under nonuniform temperature distribution. The results are compared to the grey wolf optimization (GWO), particle swarm optimization (PSO), and cuckoo search (CS) algorithm. Faster global maximum power point tracking (GMPP) within $381 \mathrm{ms,}$ higher power tracking efficiency of up to $99.93 \%$, and least oscillation $\approx 0.8 \mathrm{~W}$ are achieved by the proposed BMO with the highest energy harvest on average. The statistical analysis further solidifies the better performance of the proposed controller with the least root mean square error (RMSE), RE, and highest SR.
\end{abstract}

Keywords: power optimization; thermoelectric generator (TEG); nonuniform temperature distribution (NTD); maximum power point tracking (MPPT); barnacles mating optimization algorithm (BMO)

\section{Introduction}

All the energy resources on earth originate from solar heat and radiation. The usage of fossil fuels has ignited global warming. To actively combat the increasingly adverse effects of global warming issues, favorable governmental policies and resources are being employed to develop alternative sources of clean energy. Renewables, specifically solar and wind, have achieved cost/watt parity with conventional coal, gas, and carbon fuelbased power generation. Among these resources, solar provides by far the most studied devices for direct conversion of solar energy in the form of photovoltaics, thermoelectric, and concentrated solar-based electrical power generation. Until now, the thermoelectric devices have been neglected due to lower density and the high cost of manufacturing. Advancement in solid-state device manufacturing and the availability of alternative cheaper durable materials have been achieved. These breakthroughs enabled TEG electrical systems to emerge as dependable renewable energy systems [1-4]. 
Being solid-state devices, TEG modules withstand very high temperatures and have long operational lives. The TEG system finds its applications in medical [5], concentrated solar, self-powered sensor [6], heat recovery, and thermal engine heat removal applications $[7,8]$. The photovoltaic modules reduce/lose efficiency at higher temperatures above room ambient conditions. The second advantage is the modularity of each module that allows scale-up configurations in total crosstied, parallel, or series combination of TEG modules for high-power-rated applications and employment on different geometries of heat sources such as ducts, pipes spheres, etc. [9]. Modularity in this situation allows three types of control action, among which centralized MPPT controllers have the advantages of being centralized in the use of fewer numbers of sensor modules, a single microcontroller for MPPT, and higher-level voltage regulations. TEG provides DC and allows smooth integration with DC converters. The DC converters provide three additional advantages. The first advantage arises from the ability to transit lower voltages to higher levels, reducing the magnitude of the current. This avoids the power losses associated with heat dissipation in the internal resistance of wiring and components. Second is the interfacing between resistive loads and TEG modules. The third and most significant for MPPT is the controllability for the reference voltage via modulated control signal for reference voltage, hence allowing an active online monitoring of MPPT operations [10,11]. Figure 1 elaborated on the physical layout of a standard TEG power generation system. The MOSFET driver circuit enforces the duty cycle control signal for optimum MPPT operation under conditions provided to the TEG system [12]. Figure 2 shows a detailed structure and layout of the electrical equivalent circuit. Figure 3a power-voltage characteristics curves elaborate on the nonlinear nature of TEG systems $[13,14]$.

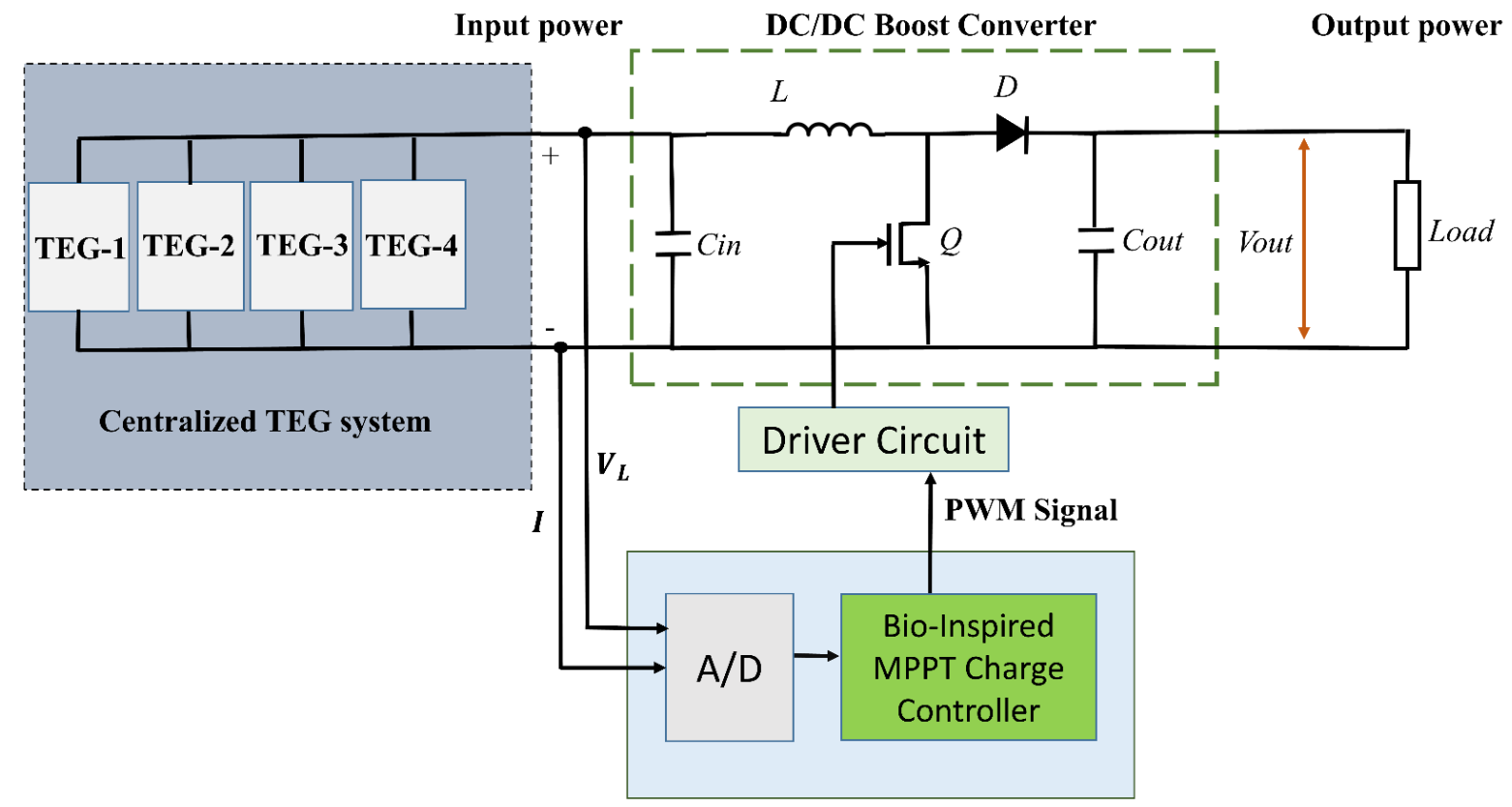

Figure 1. TEG modules interfaced with boost converter through MPPT control. 


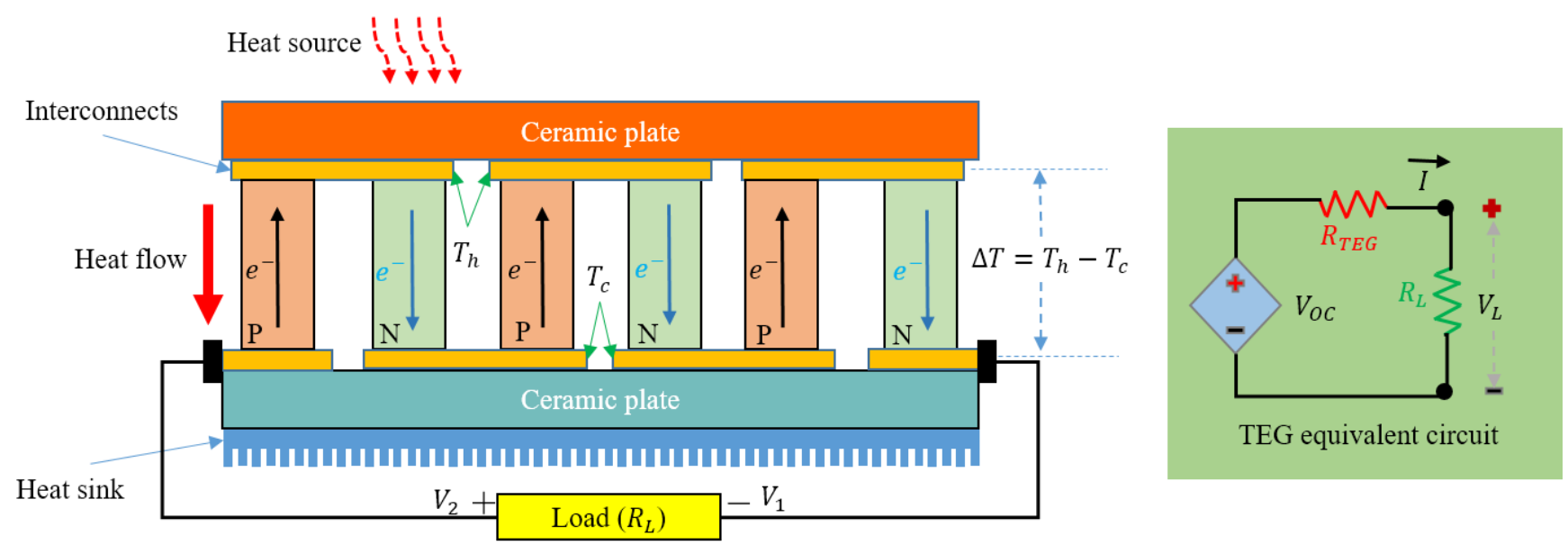

Figure 2. Equivalent model of TEG module.

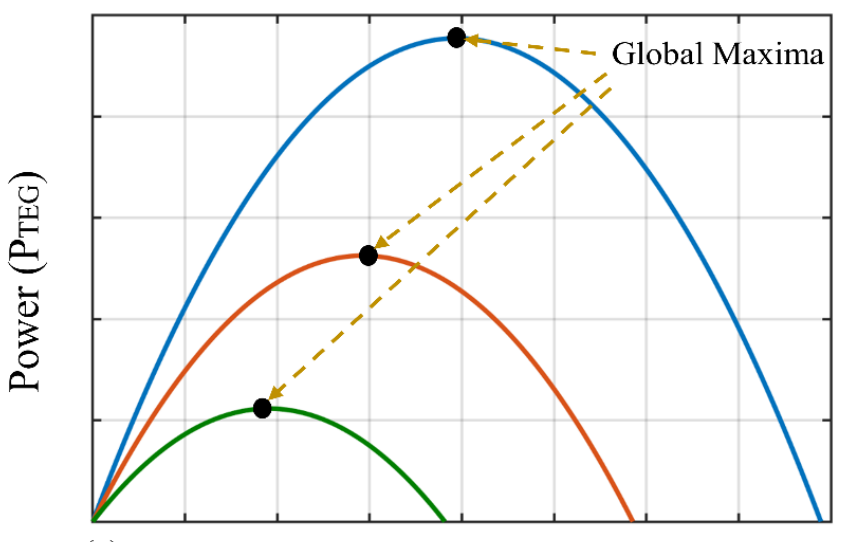

(a)

Terminal Voltage $\left(\mathrm{V}_{\mathrm{L}}\right)$

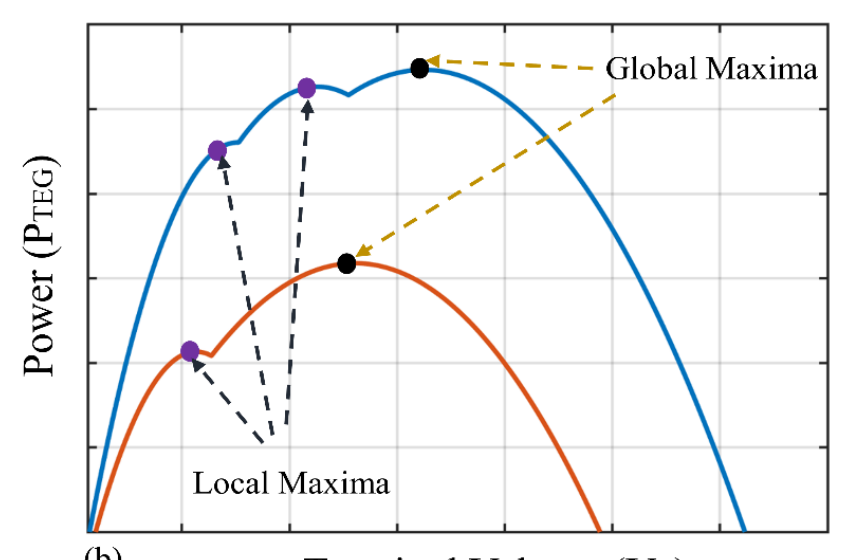

(b)

Terminal Voltage $\left(\mathrm{V}_{\mathrm{L}}\right)$

Figure 3. (a) Total power vs. terminal voltage relationship under uniform temperature distribution. (b) Total power vs. terminal voltage relationship under nonuniform temperature distribution.

In the literature, renewables such as photovoltaics (PV), TEG systems, and wind energy conversion systems (WECS) utilize several optimization controllers [15]. MPPT control is divided into two groups: namely, intelligent and classical. The classical techniques have subclasses of gradient based and analytical based. The physical parameters of the base system such as PV, TEG, or wind turbine are utilized. The operating conditions are mathematically correlated with the best operating point. The system is forcefully operated on a predetermined/estimated set point. The short-circuit current, pilot cell, fractional short circuit current (FSCC), fractional open-circuit voltage (FOCV), and PID control are analytical techniques. The physical modeling of a TEG is conducted using the Seebeck coefficient and temperature difference. These parameters are provided by the TEG manufacturers and are highly dependent upon physical dimensions. Maximum power transfer to the load is delivered by a load-resistance match following the maximum power transfer principle. TEG systems drawback for deterministic operating reference is that parameters such as short-circuit current and open-circuit voltage are sensitive to the operating conditions. The efficiency of operation is highly compromised when the operating conditions change $[16,17]$. Power loss to the load occurs during periodic adjustment of the best operating point [12]. Hence, this is considered an offline MPPT control and is, therefore, not suited for continued MPPT action under non-uniform temperature distribution (NUTD) conditions [18].

The MPPT control using a gradient-based decision process, i.e., incremental conductance (IC), perturb and observation $(\mathrm{P} \& \mathrm{O})$, gradient descent hill climbing $(\mathrm{HC})$, etc. These algorithms are fast and simple to implement. Disadvantages are caused by a single operat- 
ing point and oscillations around the GMPP and the inability to detect global maximum power point (GMPP) under NUTD [19].

The MPPT control technique inspired by modern intelligent methods can be further classified into four groups. These are as follows: machine learning (ML) based, fuzzy logic control (FLC) based, swarm intelligence (SI) based, and deep-learning-based employing neural networks (NN). ML and NN techniques require training using actual data of input conditions and achieved output. The FLC requires a comprehensive set of rules and a thorough examination of the base system for minimum shading and mismatch loss through improved fill factor [20]. FLC has a complex implementation in real-world applications due to nonlinearities and is computationally expensive for low-cost microcontrollers [21,22]. The deep learning techniques utilize the NN. The NN and ML techniques are suitable for the nonlinear optimization problem. Their limitations are caused by the availability of data sets, outliers in features of data sets, and the efficiency of the training process [23].

SI-based MPPT techniques exhibit an intrinsic ability to avoid the local maxima power point (LMPP) trap. Working with fitness functions allows for a less accurate mathematical model of the TEG system under consideration. Fitness functions are simple and do not require data for the improvisation of cost functions. These qualities are well suited for MPPT control of TEG systems. The PSO by far is the most studied SI optimization [24].

The TEG modules can be arranged in a series, parallel, or total crosstied (TCT) configurations physically. The DC converters corresponding to functionality can be termed as distributive, modular, or centralized. A centralized DC converter is used in this study. In a series of connected sources, the NUTD condition produces a mismatching current [25]. The performance of each series string is limited by the least performing TEG module. The module with low current generation acts as a resistive load where extra power of the whole string is dumped in the form of heat $\left(H=I^{2} R T\right)$ [26]. This may permanently damage the modules. As a safety measure, antiparallel bypass diodes are added. The least productive modules are isolated by the autonomous triggering of positively influenced diodes. The activation of bypass diode at different voltage levels makes the MPPT solution complex. Under NUTD, this may be caused by different temperatures, heat flow rates, or the geometry of the heat source. Complexity can be lowered using distributive low-rating converters. A relatively high generation efficiency can be achieved [27,28]. The cost and complexity of the control action become higher. Centralized MPPT control TEG system minimizes the costs due to fewer hardware components. Therefore, the chances of equipment failure are also lower. Simpler scalability is an additional advantage of this topology [29].

The SI algorithms are motivated by the mathematical modeling of natural processes. Metaheuristic algorithms are a powerful tool for numerical optimization of complex problems using the gradient-free process of GMPP location [30]. MPPT methods of PV systems are similar to TEG systems. The gray wolf optimizer (GWO), genetic algorithm (GA) [31], whales optimization algorithm (WOA), particle swarm optimization (PSO) [32], memetic salp swarm algorithm (MSSA) [33], Ligo-like reconfiguration [34], and dynamic leader collective intelligence (DLCI). In Reference [35], the fast atomic search optimization (FASO) is studied. In this optimization process, multiplier weights are adjusted to fitness similar to the PSO. Recently, the decay factor is utilized to minimize the oscillations for the step size in adoptive compass search (ACS) in Reference [36]. The fitness function is affected and influenced by several parameters. Slow tracking speed causes dynamic power loss. Although GMPP is located in the search space, a still quicker settling time and zero oscillations enhance the energy harvest over a large duration of time [37]. In this study, a stochastic algorithm, namely Barnacle Mating Optimization algorithm (BMO), is suggested as a means to finding the global maximum power point of a thermos electric generator. The control is achieved by varying the duty cycle of the boost converter according to the results of the BMO algorithm [38]. The main features of BMO are listed below:

- We proposed an MPPT technique that requires less iteration to track the GM with only one tuning parameter. The proposed MPPT technique can effectively track GM under NTD with high efficiency and reduce power loss. 
- The implementation complexity of the proposed technique is very low and can be implemented on a low-cost controller. Results of multiple cases demonstrate the superiority of the BMO techniques in terms of fast tracking and quick settling at GM.

The rest of the paper is organized as follows: modelling of TEG is explained in Section 2; proposed MPPT technique is presented in Section 3; Section 4 explains the BMO-based control for MPPT; extensive case study with statistical analysis is presented in Section 5; and the paper is concluded in Section 6.

\section{Modeling of TEG System}

\subsection{TEG Module Modeling}

Figure 2 shows an equivalent model and physical layout of a single TEG cell. Table 1 provides the electrical properties of TEG module TE-MOD-22W7V-56. The electrical layout of the TEG cell as given in Figure 2 behaves as a voltage source with a series resistance $\left(R_{T E G}\right)$. The open-circuit voltage $V_{O C}$ can be presented as shown in Equation (1). The $V_{O C}$ and $R_{T E G}$ vary with temperature difference $(\Delta T)$ between hot sides $\left(T_{h}\right)$ and the cold side $\left(T_{c}\right)$ plates [29].

$$
V_{o c}=\alpha_{p n}\left(T_{h}-T_{c}\right) n=\alpha_{p n} \Delta T n
$$

where $\alpha_{p n}$ is the Seebeck coefficient and $n$ is the TEG modules connected in series [39].

Table 1. Electrical characteristics of TEG Module (TE-MOD-22W7V-56).

\begin{tabular}{ccc}
\hline Parameter & Conditions & Value \\
\hline Power & $T_{h}=300, T_{c}=30 @$ Matched Load & $22 \mathrm{~W}$ \\
\hline Open-circuit voltage & $T_{h}=300, T_{c}=30$ & $14.4 \mathrm{~V}$ \\
\hline Matched load voltage & $T_{h}=300, T_{c}=30$ & $7.2 \mathrm{~V}$ \\
\hline Internal resistance & $T_{h}=300, T_{c}=30$ & $1.1 \Omega$ \\
\hline Matched load current & $T_{h}=300, T_{c}=30 @$ Matched Load & $3.0 \mathrm{~A}$ \\
\hline
\end{tabular}

The TEG elements are a combination of the Thompson effect and Peltier junction. When current passes through each element, it generates or absorbs heat due to temperature gradient. For an average temperature (T) in Equation (2), the Thompson coefficient $\tau$ is given as

$$
\tau=T \frac{d_{\alpha p n}}{d T}
$$

To precisely model the TEG module, Thompson's effect is nonzero and may vary significantly [17]. Thus, dynamic behavior is incorporated into the Seebeck coefficient using Equation (3).

$$
\alpha(T)=\alpha_{o}+\alpha_{1} \ln \left(\frac{T}{T_{0}}\right)
$$

where $\alpha_{o}$ is a basic Seebeck coefficient for the rate of variation represented by $\alpha$ and $T_{o}$ is the reference temperature. The power generation of TEG is given by Equation (4) as

$$
P_{T E G}=\left(\alpha_{p n}\right)^{2} \frac{R_{2}}{\left(R_{L+} R_{T E G}\right)^{2}}
$$

where $R_{L}$ and $R_{T E G}$ are the load and internal resistance.

\subsection{Configuration of TEG System}

In practice, several topologies are utilized for higher power rating. Cost-effective centralized TEG configuration has multiple TEG modules in series/parallel combinations. The power losses caused by series-parallel connected power sources are minimized by 
the centralized MPPT controller in this study $[27,33,40,41]$. Centralized TEG system is presented in Figure 4.

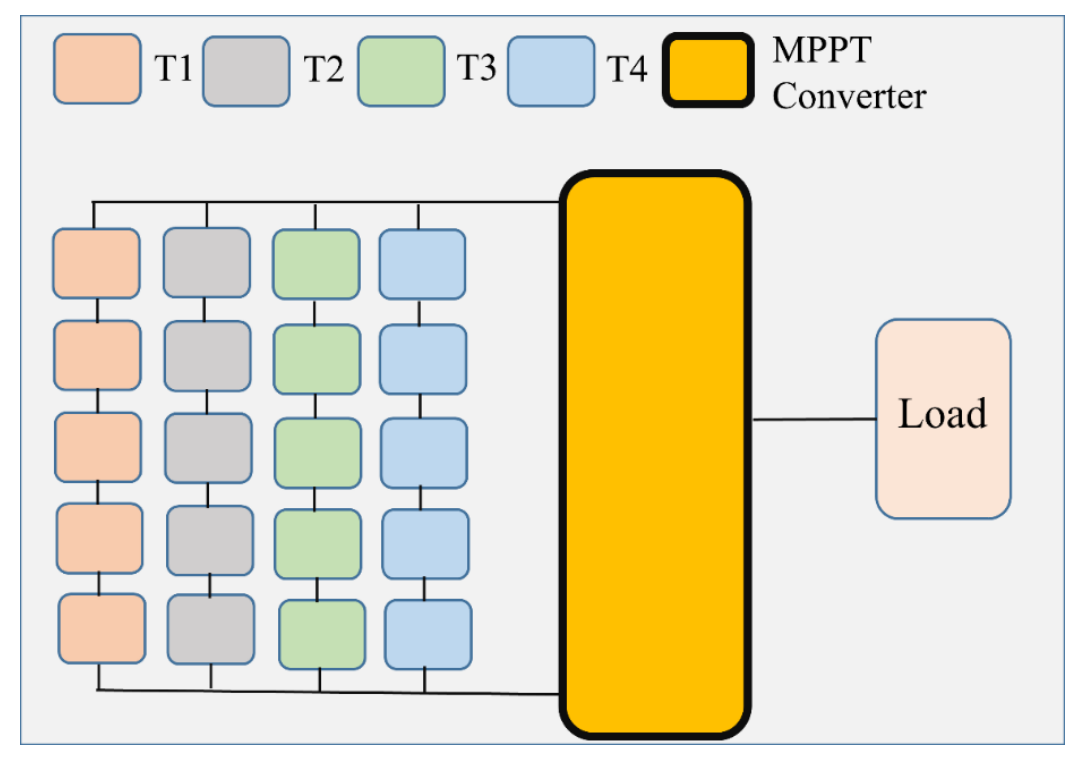

Figure 4. Centralized TEG system configuration.

\subsection{Modeling of TEG System under NTD Condition}

TEG module is exposed to different temperature magnitudes and heat flow rates due to environmental and operational conditions [42]. For a series-parallel combination of TEG modules, Equation (5) provides the output current as

$$
I_{i}=\left\{\begin{array}{c}
\left(V_{o c i}-V_{L i}\right) \frac{I_{s c i}}{V_{o c i}}=I_{s c i}-\frac{V_{L i}}{R_{T E G i}} \\
0 \text { otherwise }
\end{array} \quad 0<V_{L i} \leq \frac{I_{s c i}}{V_{o c i}}\right.
$$

where for the $i$ th module in a series connection the $V_{o c i}$ is the open-circuit voltage, $V_{L i}$ is the load voltage, $I_{s c i}$ is the maximum short-circuit current, and $R_{T E G i}$ is total internal resistance. The output power $P_{T E G i}$ of each module is given by Equation (6)

$$
P_{T E G i}=\left\{\begin{array}{c}
V_{L i} I_{i}=I_{s c i} V_{L i}-\frac{I_{s c i}}{R_{T E G i}} \text { if } 0<V_{L i} \leq \frac{I_{s c i}}{V_{o c i}} \\
0 \text { otherwise }
\end{array}\right.
$$

The total power of the TEG module is

$$
P_{T E G E}=\sum_{i=1}^{N} P_{T E G i}
$$

Figure $3 \mathrm{~b}$ shows the $\mathrm{P}-\mathrm{V}$ characteristics under the nonuniform distribution of heat source where series-connected temperature-dependent sources add different magnitudes of current in a series connection. To maximize the current flow across series-connected TEG, module bypass diodes are utilized. Each bypass diode triggers at a different voltage level [43]. This condition makes this nonlinear problem of power maximization (shown in Figure 3a) into a more complex multisolution nonlinear monotonic relationship between $\mathrm{P}-\mathrm{V}$. It is mandatory to generate a reference voltage for a centralized DC boost converter to force the TEG system to operate at a unique GMPP for maximum extracting of power [44]. These multiple maxima are termed local maxima and global maxima $[45,46]$. Therefore, under NTUD, BMO is required to generate reference voltage for maximizing power/energy output [47-50]. 


\section{Proposed Technique}

In this section, the $\mathrm{BMO}$ is modeled for the optimization process with a centralized controller approach.

\subsection{Inspiration}

The micro-organisms named barnacles have existed since the Jurassic times. Barnacles can swim immediately after their birth, and whilst growing shells, they attach themselves to the objects in the water. Amongst them, most barnacles are hermaphroditic in nature, which means they have both male and female reproduction tendencies. The most common species out of 1400 species are called acorn barnacles.

\subsection{Initialization}

In BMO, the solution candidates are barnacles. This population can be initialized as

$$
D=\left(\begin{array}{ccc}
d_{1}^{1} & \cdots & d_{1}^{N} \\
\vdots & \ddots & \vdots \\
d_{n}^{1} & \cdots & d_{n}^{N}
\end{array}\right)
$$

where $n$ is the population size, and $N$ represents the number of control variables. The boundary control needs to be applied to the population using the following

$$
\begin{aligned}
u b & =\left[u b, \ldots, u b_{i}\right] \\
l b & =\left[l b, \ldots, l b_{i}\right]
\end{aligned}
$$

where $l b$ and $u b$ are the lower and upper bound of $i$ th variable.

\subsection{Selection Process}

The selection process for mating of two barnacles depends upon the length of their penis size, $p l$. The selection process is based upon the following assumptions.

Assumption 1. The selection process is performed randomly, but the restriction is applied on the length of penis size, $p l$.

Assumption 2. Each barnacle can contribute its sperm as well as receive it from other barnacles, and each barnacle can be fertilized by one barnacle at one time.

Assumption 3. If the selection process selects the same barnacle both times, a phenomenon is known as self-mating, the mating process does not occur, and no offspring is generated.

Assumption 4. If the selection at a certain iteration is greater than pl, the sperm casting process takes place.

Considering the rules undertaken due to assumptions, the exploitation phase (Assumption 1-2) and exploration (Assumption 4) are imposed in the optimization process. The selection of search agents takes place using

$$
\begin{aligned}
& \text { barnacle_d }=\operatorname{randperm}(n) \\
& \text { barnacle_m }=\operatorname{randperm}(n)
\end{aligned}
$$

\subsection{Re-Production}

The reproduction phase of BMO is slightly different as compared to other evolutionary algorithms. To produce the new variables, the following equations are used in the reproduction phase.

$$
d_{i}^{\text {new }}=P d_{b a r \_d}^{N}+q d_{b a r_{\_} m}^{N}
$$


where $q=(1-P)$ and $P$ is selected randomly from [0,1] [51] and $d_{b a r_{-}}^{N}$ is the dad and $d_{b a r m}^{N}$ is the mum variable chosen from Equation (11) and Equation (12), respectively. $P$ and $q$ decide the percentage of the dad and mum's characteristics that are going to be added in the offspring. To determine the exploration and exploitation process, $p l$ plays an important task. The exploitation process is governed by Equation (13). In BMO, exploration phase mimics the sperm cast. It is treated by Equation (14) and occurs when the selection of barnacles to be mated becomes greater than the $p l$ for $r a n d()$ between $[0,1]$

$$
d_{i}^{\text {new }}=\operatorname{rand}() \times d_{\text {barnacle } \_m}^{n}
$$

\section{BMO-Based Control of TEG System}

\subsection{Control Variable}

To track MPP in a centralized TEG system under NTD, the terminal voltages are varied. To vary the terminal voltages on the other hand and to effectively deliver the power to the load at MPP requires a DC-DC boost converter as an interface. By varying the duty cycle of the boost converter, the terminal voltages can be varied, resulting in the tracking of MPP. This tuning of duty cycle is performed by BMO-based MPPT control, and the generated duty cycle lies between 0 and 1 , that is, $\left(0<D_{c}<1\right)$. The upper and lower boundary is defined in the MPPT control technique as

$$
D_{c}^{\text {new }}=\left\{\begin{array}{l}
0 \text { if } D_{c}^{\text {new }}<0 \\
1 \text { if } D_{c}^{\text {new }}>1
\end{array}\right.
$$

The initial population of BMO is located on the whole search space to effectively explore and search for the global maxima.

\subsection{Fitness Function}

Fitness function is considered depending upon the quality of the solution. As stated in Equation (16), the explorative solution is always feasible. The conversion of the objective function into the fitness function is the best choice. For the effective tracking of the fitness function for the MPPT control, the TEG system is

$$
\operatorname{Fitness}(x)=V_{i}\left(t_{k}\right) I\left(t_{k}\right)
$$

where $I\left(t_{k}\right)$ and $V_{L}\left(t_{k}\right)$ are the outputs of the current and terminal voltage at the time slot $t_{k}$. These voltage and current measurements are obtained using voltage and current sensors.

\subsection{Execution Procedure}

The overall execution of the procedure of BMO-based MPPT control for the TEG system is presented in Figure 5 as flow chart, and the step-wise implementation of pseudocode is given in Figure 6. 


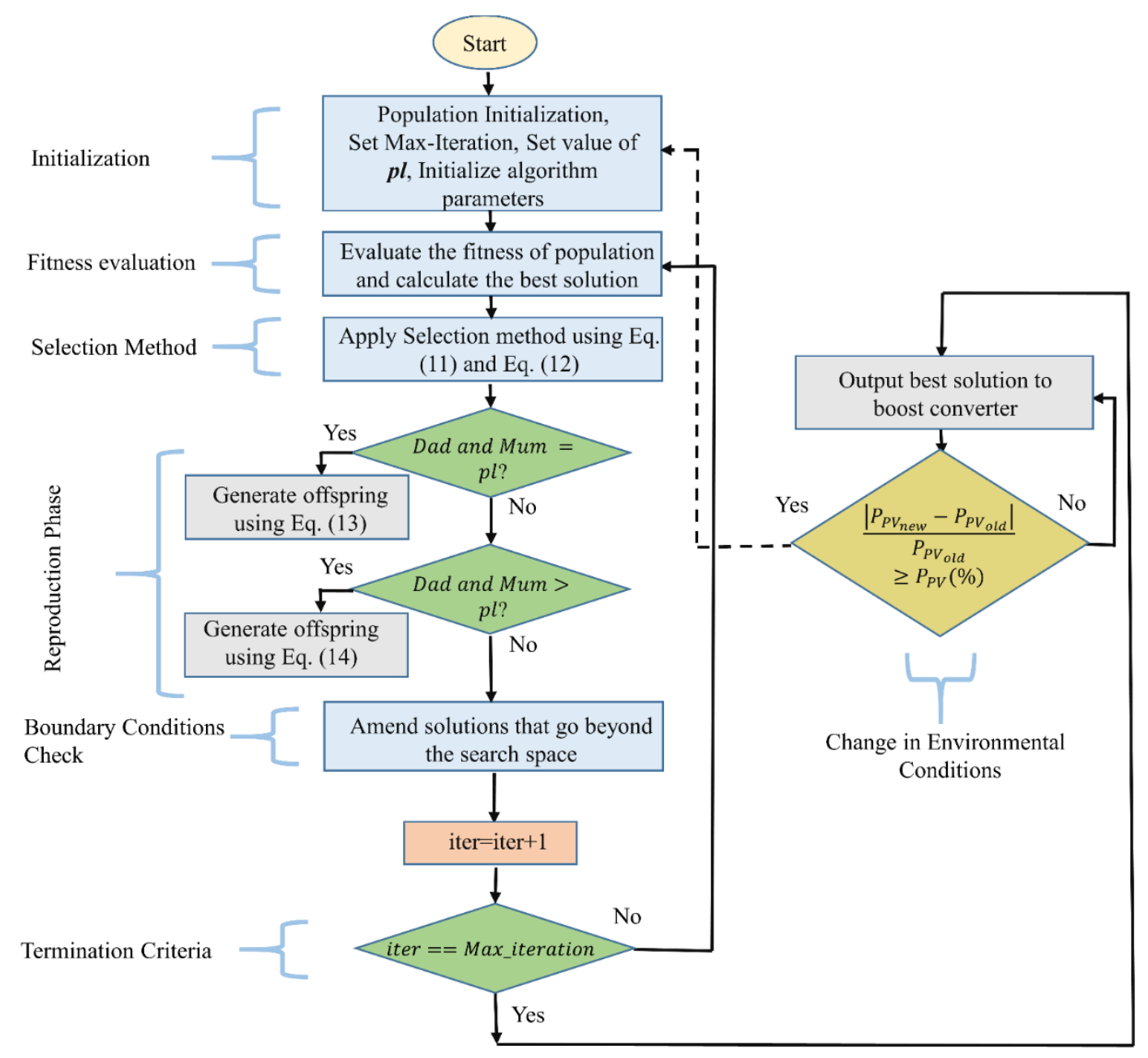

Figure 5. BMO-based MPPT control flow chart.

initialize population $d_{i}, i=1,2, \ldots, N$

evaluate the fitness of each barnacle

sort the solutions and find the best solution

while(iter<iter_max)

set the value of $\mathrm{pl}$

select using Eq. (11) and Eq. (12)

if slection of Dad and mum $=p l$

for each variable

end for

generate offspring using Eq. (13)

else if selection of Dad and mum $>p l$

for each variable

generate offspring using Eq. (14)

end for

end if

apply boundary conditions on updated solution

calculate fitness and sort solution to update the best solution iter $=$ iter +1

end while

Return best solution

Figure 6. Pseudo code of BMO for TEG MPPT controller design. 


\section{Case Studies}

The performance of the BMO-based MPPT control technique is evaluated against PSO, GWO, and CS. Different case scenarios are employed, that is, start-up test, vast varying temperature, and stochastic temperature variation. These conditions mimic industrial applications. For comparative analysis, the statistical indices and MPPT rating system is introduced. An experimental setup with a low-cost emulator design inn was studied for real-world application validation [51,52].

The maximum iteration number and population sizes are 50 and 4, respectively. The sampling time is $0.02 \mathrm{~s}$, which corresponds to the settling time of the algorithm - updated duty cycle using PWM signal of the DC-DC boost converter. Since P\&O and other hill climbing techniques fall in the LM trap and cannot find the GM, the techniques are not used for the comparison.

\subsection{Startup Test}

In this case, MPPT performance is tested under NTD conditions. The hot and cold side temperatures for the $4 \times 1$ configuration are 219-47, 159-47, 111-30, and $73-19{ }^{\circ} \mathrm{C}$ from top to bottom. Figures 7 and 8 tracked power by MPPT techniques, which is clear evidence of no oscillations produced by BMO at GM.

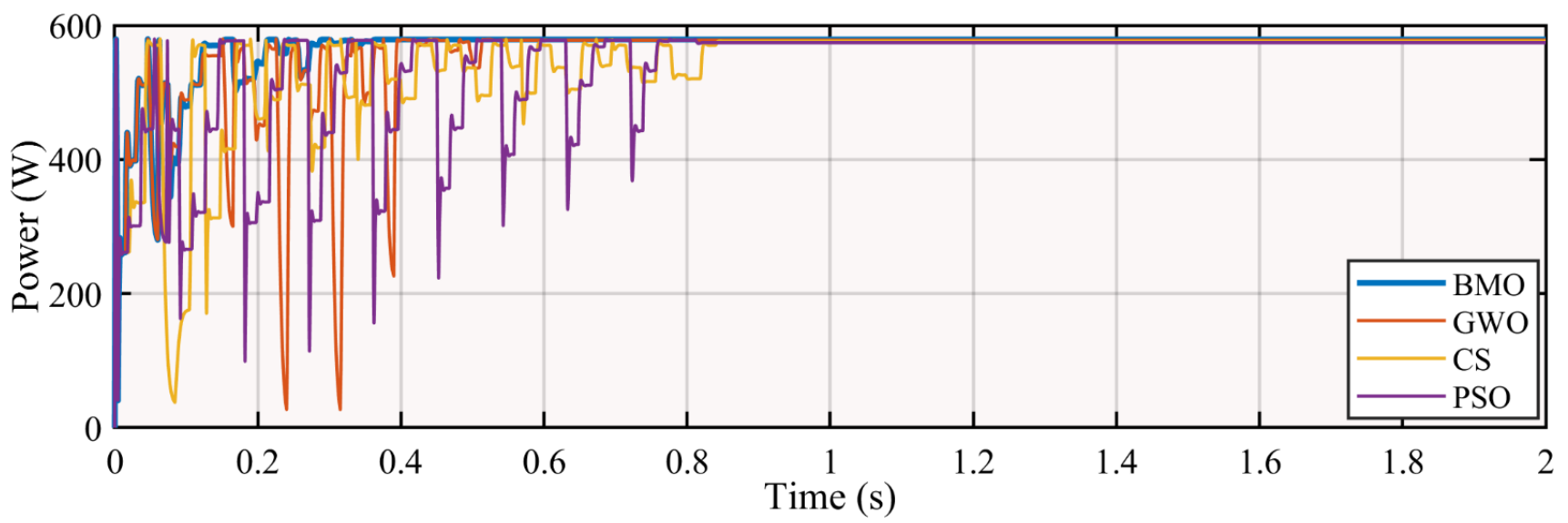

Figure 7. Competing techniques Power Case-1.

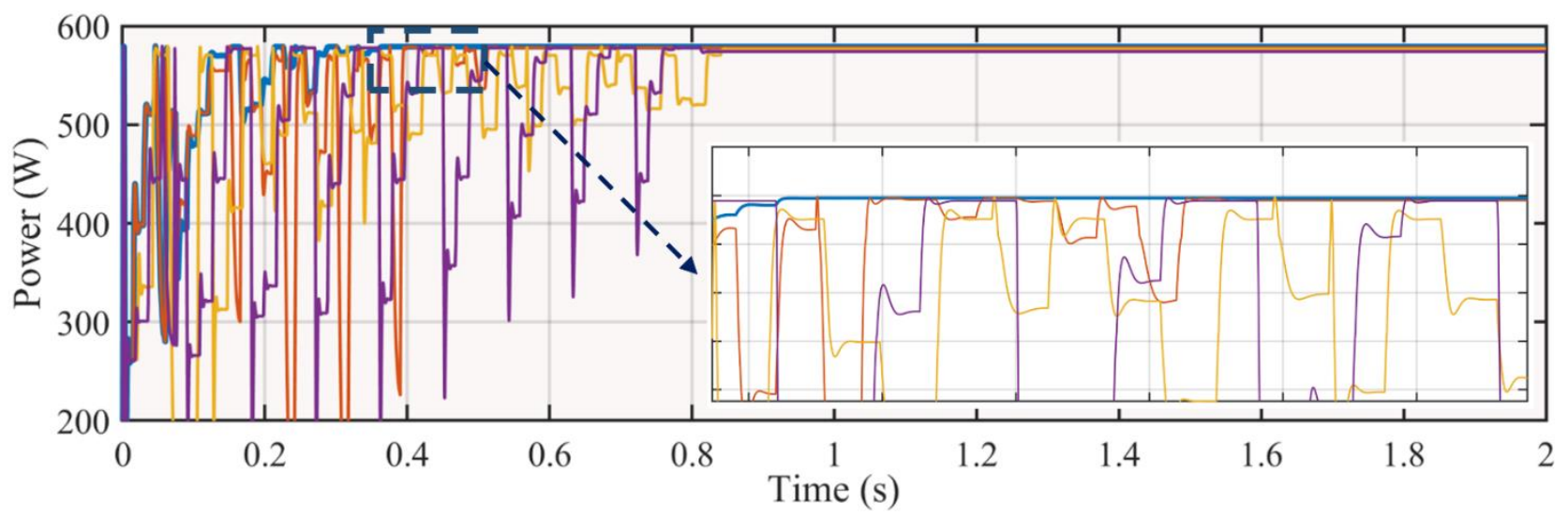

Figure 8. Competing techniques zoomed in Power Case-1.

Large oscillations can be observed in PSO. These oscillations are reduced in GWO using the parameter "a" reduced over the iterations.

Table 2 provides the summary of the power tracked by competing techniques where the highest power achieved by BMO at $579 \mathrm{~W}$, followed by GWO $578 \mathrm{~W}, \mathrm{CS} 576.6 \mathrm{~W}$, and PSO i574.2 W. The efficiency with respect to MPP is $99.93 \%$ by BMO, $99.75 \%$ by 
GWO, $99.51 \%$ by CS, and $99.10 \%$ by the PSO. The time taken by BMO takes $381 \mathrm{~ms}$ for GM tracking, $149 \mathrm{~ms}$ faster as compared to the GWO. CS takes $469.1 \mathrm{~ms}$ more to settle at GMPP with negligible fluctuations showing the slowest response to the NUT distribution is given in Figures 9 and 10, respectively. A comparison of voltage and current transients is presented in Figures 11 and 12, respectively.

Table 2. Case- 1 results.

\begin{tabular}{cccccc}
\hline Tech. & $\begin{array}{c}\text { Tracking } \\
\text { Time }(\mathbf{s})\end{array}$ & $\begin{array}{c}\text { GM Power } \\
\mathbf{( W )}\end{array}$ & $\begin{array}{c}\text { Tracked } \\
\text { Power }(\mathbf{W})\end{array}$ & $\begin{array}{c}\text { Efficiency } \\
\mathbf{( \% )}\end{array}$ & $\begin{array}{c}\text { Energy } \\
\mathbf{( W \cdot s )}\end{array}$ \\
\hline BMO & 0.3810 & 579.4 & 579 & 99.93 & 1137 \\
\hline GWO & 0.5300 & 579.4 & 578 & 99.75 & 1110 \\
\hline CS & 0.8501 & 579.4 & 576.6 & 99.51 & 1085 \\
\hline PSO & 0.8231 & 579.4 & 574.2 & 99.10 & 1073 \\
\hline
\end{tabular}

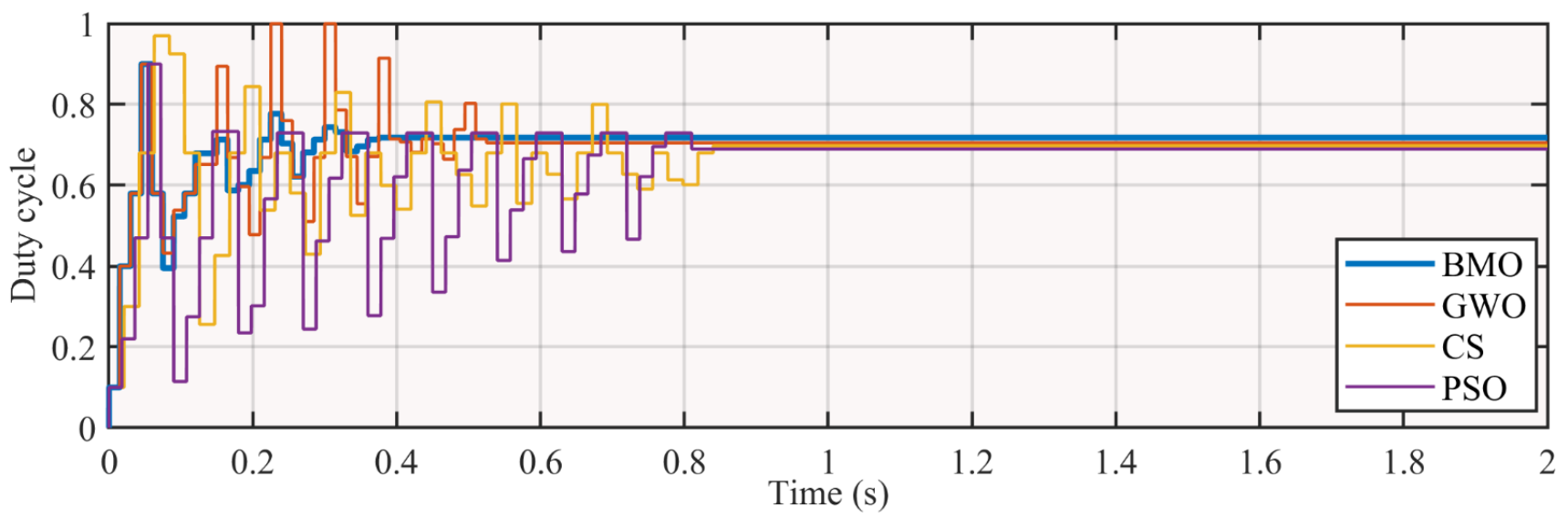

Figure 9. Competing techniques duty cycle Case-1.

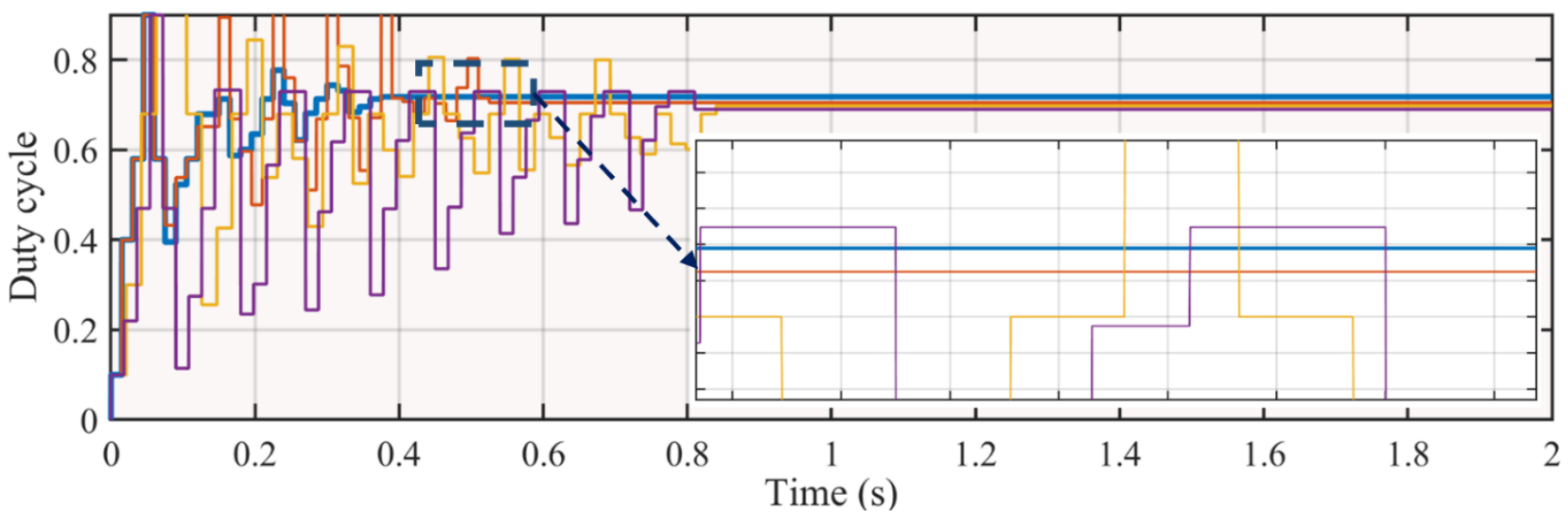

Figure 10. Competing techniques zoomed in duty cycle Case-1. 


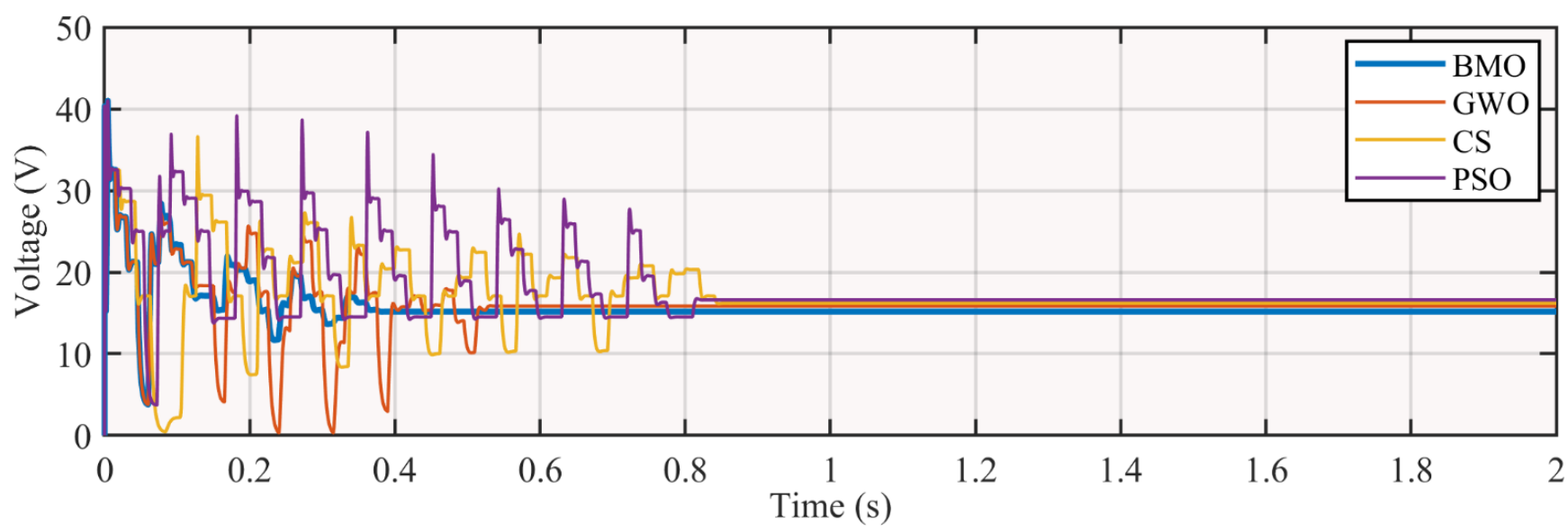

Figure 11. Competing techniques voltage Case-1.

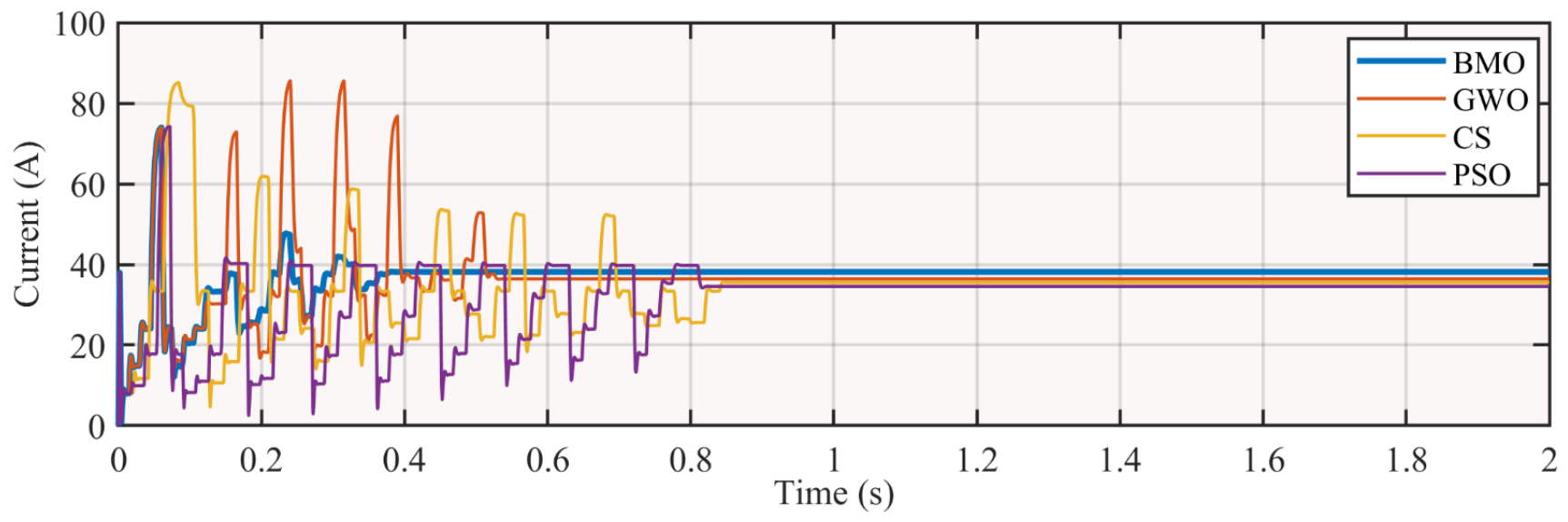

Figure 12. Competing techniques current Case-1.

Extraction of energy is also an important parameter for the comparison and Figure 13 shows that BMO extracts the highest energy due to effective explorative and exploitive behavior.

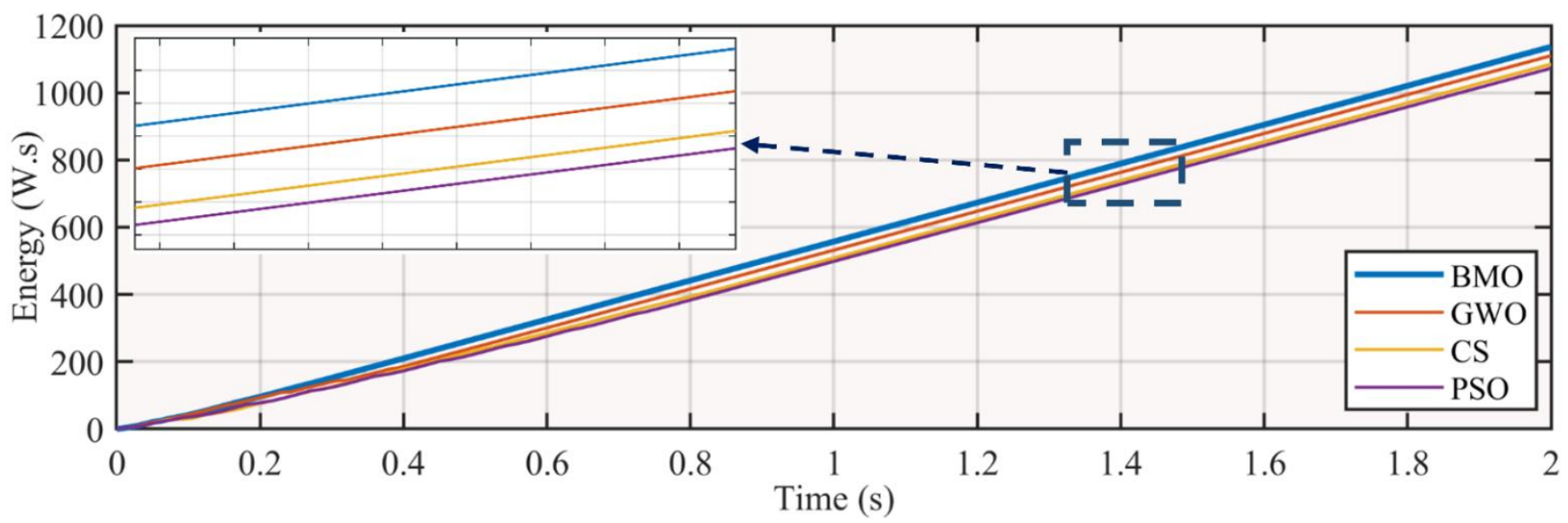

Figure 13. Competing techniques energy Case-1.

\subsection{Fast-Changing Temperature}

This case is presented to check the robustness of the MPPT techniques. The cold-side and hot-side temperatures are set to different variation curves as shown in Figures 14 and 15, respectively. The temperature changes after every $2 \mathrm{~s}$. The performance of MPPT techniques is presented in Table 3. 


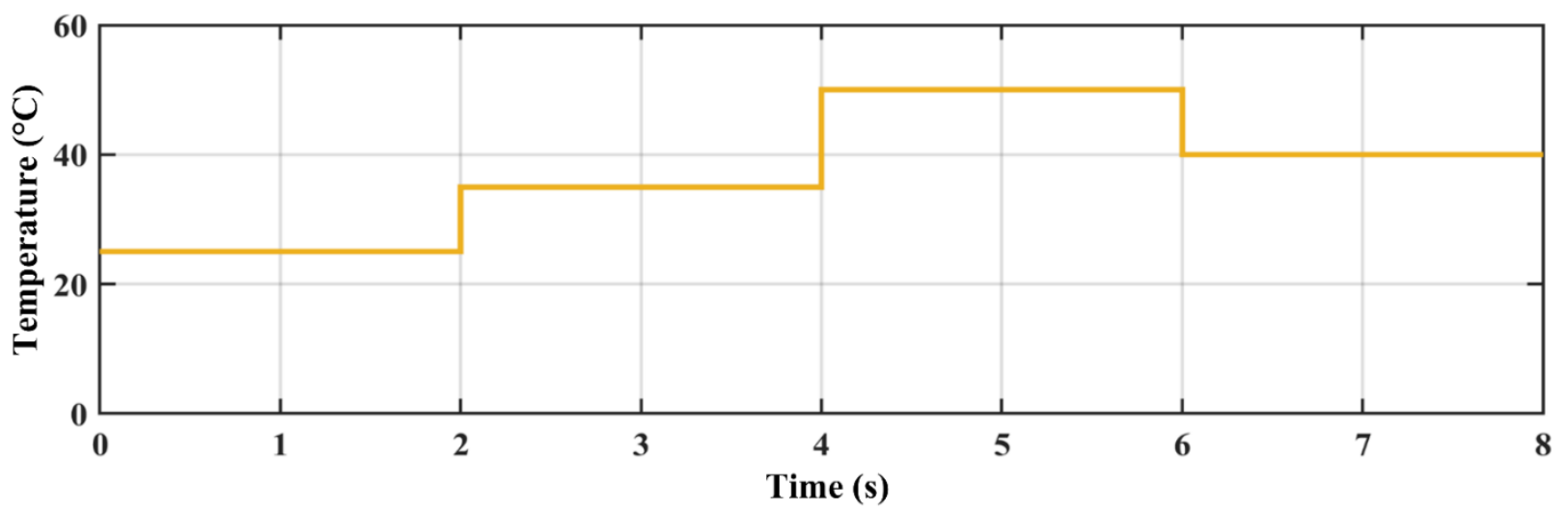

Figure 14. Change in cold-side temperature w.r.t time.

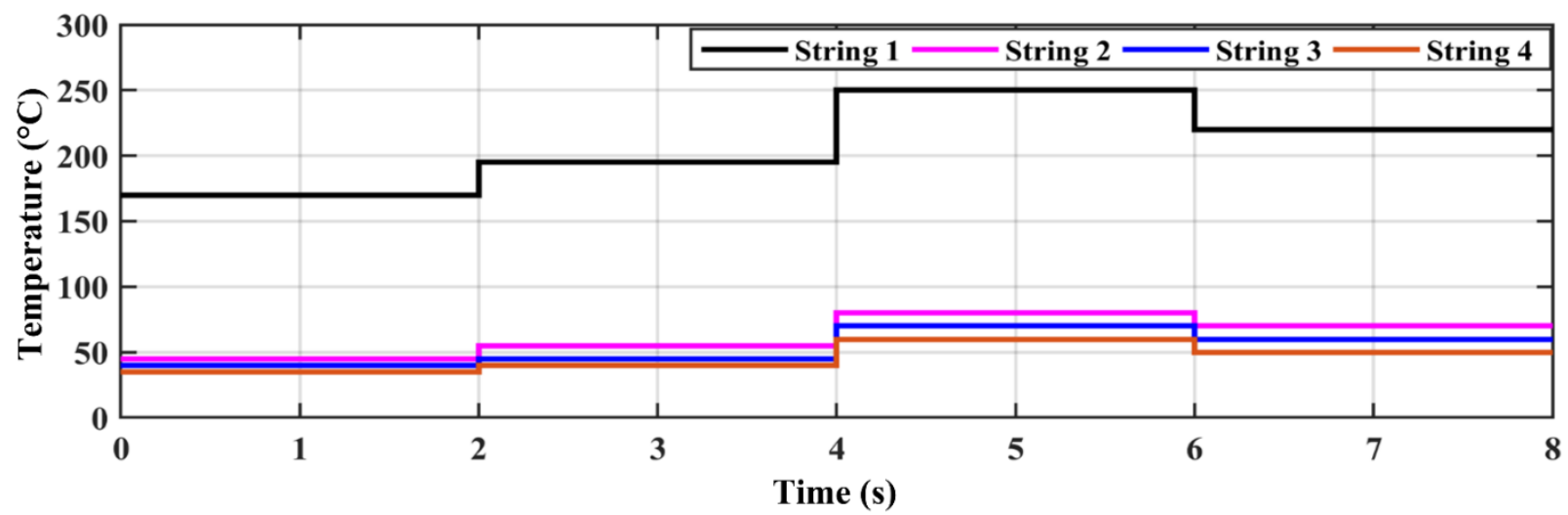

Figure 15. Change in hot-side temperature w.r.t time.

Table 3. Case-2 results.

\begin{tabular}{cccccc}
\hline Tech & $\begin{array}{c}\text { Avg. Tracking } \\
\text { Time (s) }\end{array}$ & $\begin{array}{c}\text { Avg. Power } \\
\text { (W) }\end{array}$ & $\begin{array}{c}\text { Avg. } \\
\text { Tracked } \\
\text { Power (W) }\end{array}$ & $\begin{array}{c}\text { Avg. Efficiency } \\
\text { (\%) }\end{array}$ & $\begin{array}{c}\text { Energy } \\
\text { (W.s) }\end{array}$ \\
\hline BMO & 0.2914 & 413.5 & 413.150 & 99.91 & 3269 \\
\hline GWO & 0.3805 & 413.5 & 412.937 & 99.86 & 3259 \\
\hline CS & 0.7200 & 413.5 & 412.425 & 99.74 & 3202 \\
\hline PSO & 0.7511 & 413.5 & 412 & 99.63 & 3216 \\
\hline
\end{tabular}

Re-initialization, explorative, and exploitative behavior of every metaheuristic technique can be observed after every $2 \mathrm{~s}$ due to temperature changes as shown in the power comparison figure in Figure 16. The zoomed-in power comparison is shown in Figure 17. The average power is a combination of steady and dynamic states. The average power tracked by BMO, GWO, CS, and PSO is $413.15 \mathrm{~W}, 412.93 \mathrm{~W}, 412.42 \mathrm{~W}$, and $412 \mathrm{~W}$, respectively. This shows that large oscillations at GM cause power loss in PSO, and BMO tracks the highest power. The tracking efficiency in this case is $99.91 \%, 99.86 \%, 99.74 \%$, and $99.63 \%$, respectively. 


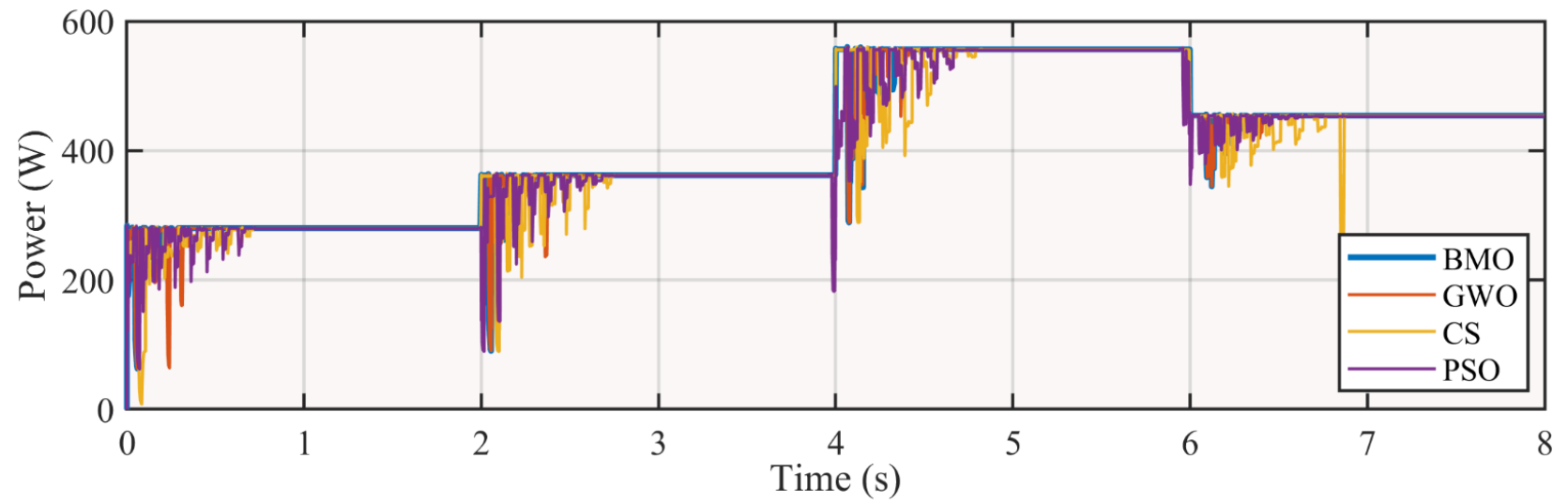

Figure 16. Competing techniques power Case-2.

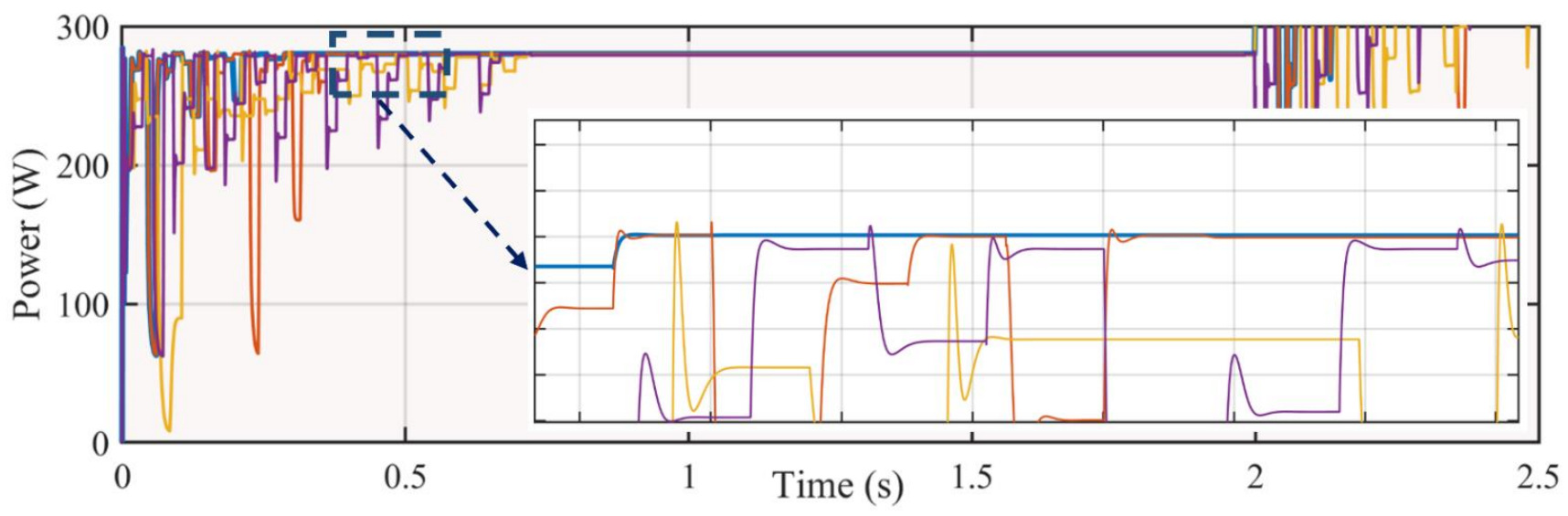

Figure 17. Competing techniques zoomed-in power Case-2.

The robustness of BMO-based MPPT technique can be validated by tracking and settling time at GM after every temperature change. The average time taken by MPPT techniques to track GM is $291.4,380.5,720$, and $751.1 \mathrm{~ms}$ as presented in duty cycle comparison and zoomed-in duty cycle comparison in Figures 18 and 19, respectively. Voltage and current transients are shown in Figures 20 and 21, respectively. Figure 22 shows energy harvest over time.

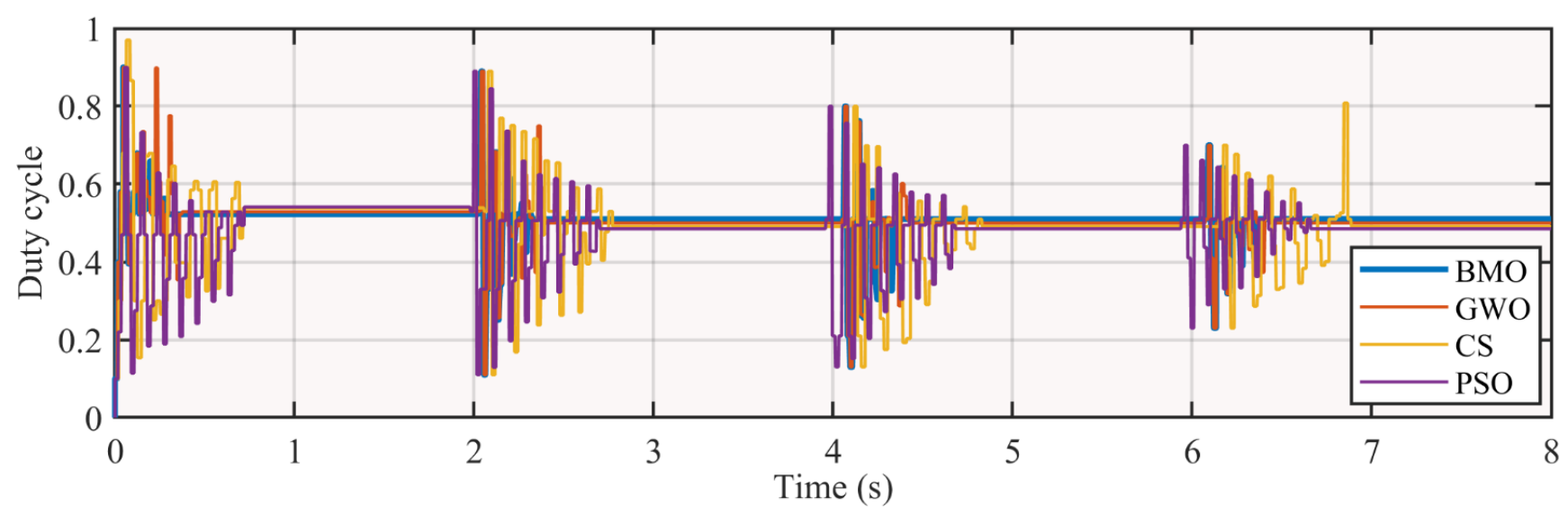

Figure 18. Competing techniques duty cycle Case-2. 


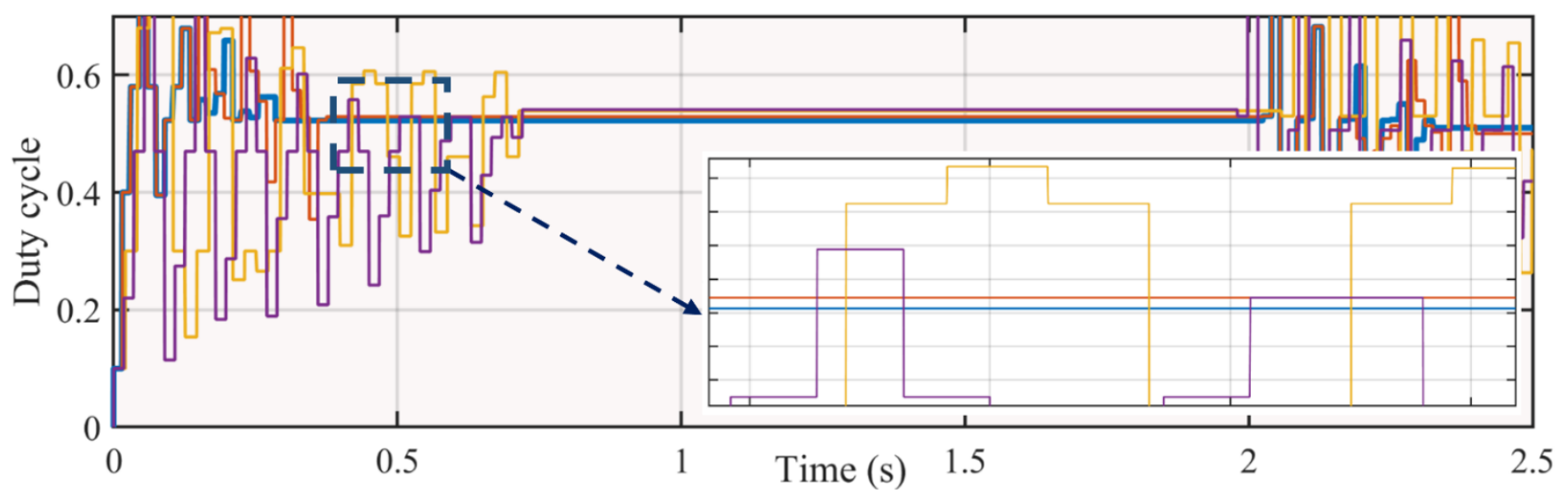

Figure 19. Competing techniques zoomed-in duty cycle Case-2.

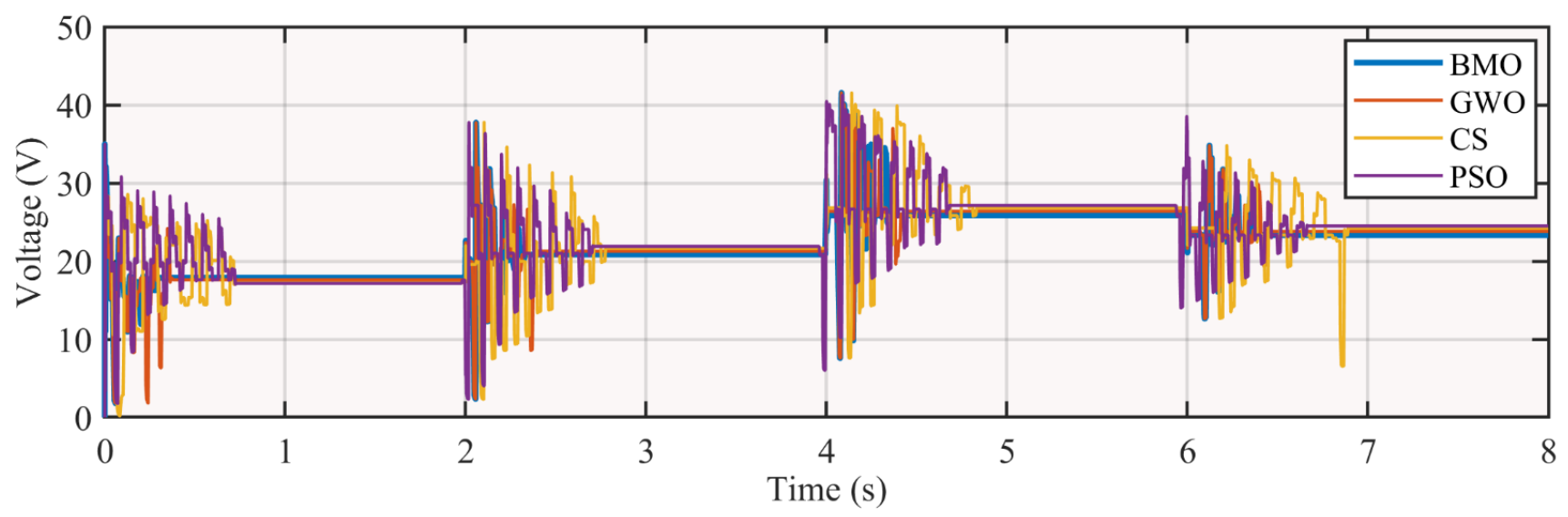

Figure 20. Competing techniques voltage Case-2.

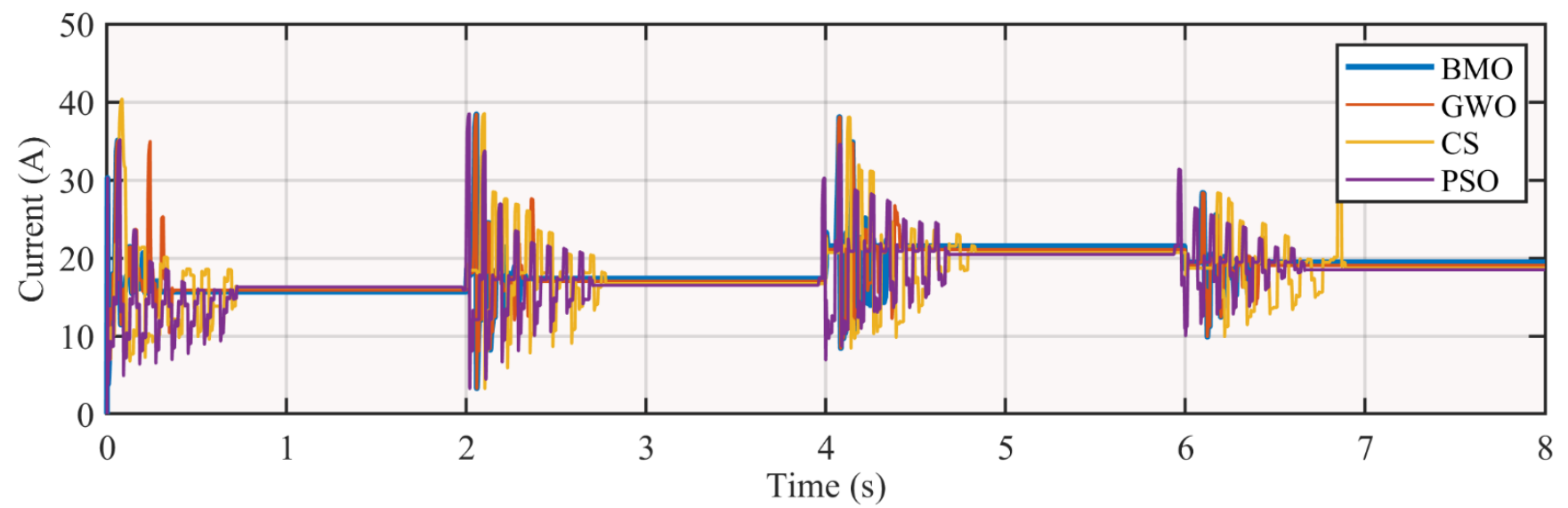

Figure 21. Competing techniques current Case-2. 


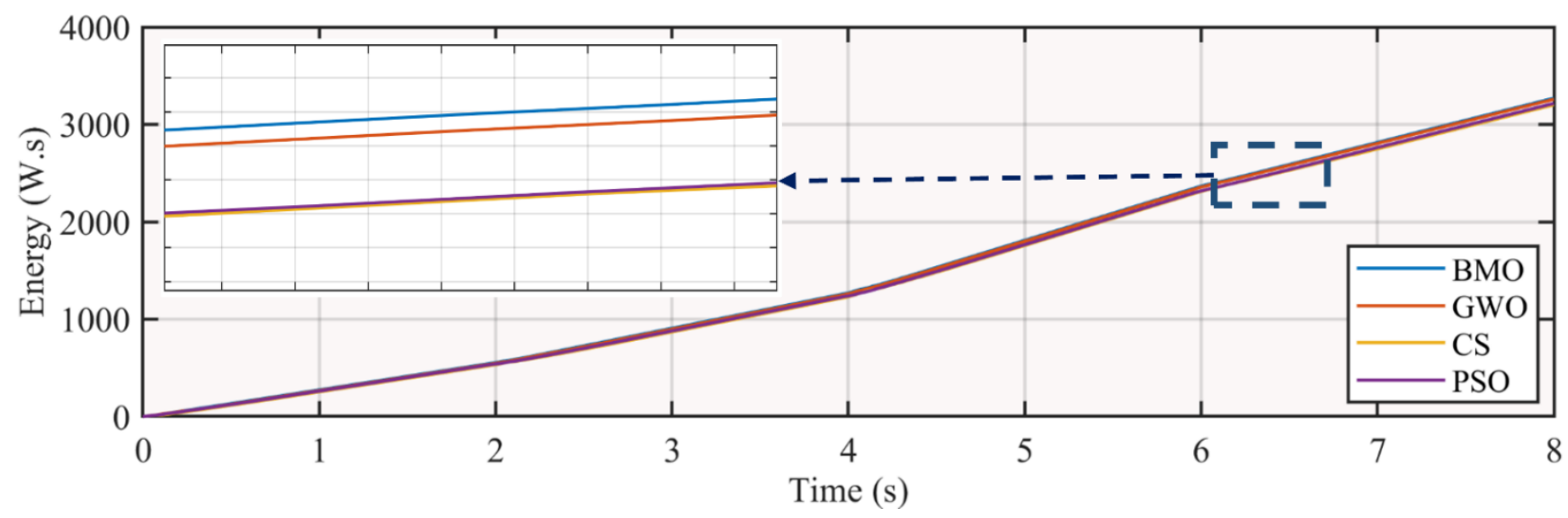

Figure 22. Competing techniques energy in Case-2.

\subsection{MPPT Rating}

Since MPPT control techniques are needed to be evaluated using the rating of techniques. This evaluates which techniques have a better rank and are effective for the usage of the MPPT control of the TEG system. The MPPT rating can be calculated using the Equation (17). The MPPT rating of all techniques is dependent upon the following factor which includes, tuning parameter required, random numbers for updating of position, the requirement of max_iteration for termination criteria, the average value of tracking time, efficiency, response to variation of load, and modification requirement in hardware.

$$
M P P T \_ \text {rating }=\frac{\text { Total achieved rating }}{7}
$$

Rating defined from 1-4 is depicting the best to worst in Table 4, which is presenting the MPPT rating comparison of all techniques. Against all the factors, the rating is awarded, and the MPPT rating is calculated using Equation (17). If tuning parameters are 1, the rating is $1 ; 2$, the rating is also $2 ; 3$ means the rating is 3 ; and greater than 4 means rating is 4 . If the number of random variables is 0 , then the rating is 1 ; if 1 , the rating is 2 ; if 2 , the rating is 3; and greater than 2 means rating is 4 . Upon achieving the termination criteria, rating 2 is assigned, and if the termination criteria not achieved, then rating 1 is achieved. If tracking time is $0-500 \mathrm{~ms}$, then rating is 1 ; if between $500-1000 \mathrm{~ms}$, then the rating is 2; if between 1000-1500 ms, then the rating is 3; and rating is 4 for greater than $1500 \mathrm{~ms}$. Rating is 1 for efficiency between $99.5 \%$ and $100 \%, 2$ for $99-99.5 \%, 3$ for $98.5-99 \%$, and 4 for less than $98.5 \%$. If hardware modification is required, then the rating is 2 , and if not required, then the rating is 1 . The last factor is a variation to the load changes [41,51]. The MPPT rating calculated for the $\mathrm{BMO}$ is 1.571 .

Table 4. Comparison of MPPT rating.

\begin{tabular}{ccccccccc}
\hline Tech & $\begin{array}{c}\text { Tuning } \\
\text { Para. }\end{array}$ & $\begin{array}{c}\text { No. of } \\
\text { Random } \\
\text { Numbers }\end{array}$ & $\begin{array}{c}\text { Termination } \\
\text { Criteria } \\
\text { Achieved }\end{array}$ & $\begin{array}{c}\text { Average } \\
\text { Tracking } \\
\text { Time (s) }\end{array}$ & $\begin{array}{c}\text { Average } \\
\text { Efficiency } \\
\mathbf{( \% )}\end{array}$ & $\begin{array}{c}\text { Modification } \\
\text { in Hardware }\end{array}$ & $\begin{array}{c}\text { Speed } \\
\text { MPPT } \\
\text { Rating }\end{array}$ \\
\hline BMO & $1(1)$ & $4(4)$ & No (1) & $0.3362(1)$ & $99.92(1)$ & No (1) & Fast & 1.571 \\
\hline GWO & $1(1)$ & $2(3)$ & Yes (2) & $0.4552(1)$ & $99.80(1)$ & No (1) & Slow & 1.714 \\
\hline CS & $1(1)$ & $2(3)$ & Yes (2) & $0.7850(2)$ & $99.62(1)$ & No (1) & Slow & 1.857 \\
\hline PSO & $3(3)$ & $2(3)$ & No (1) & $0.7871(2)$ & $99.36(2)$ & No (1) & Very slow & 2.285 \\
\hline
\end{tabular}




\subsection{Statistical Analysis}

Robustness and sensitivity of all techniques inspected by relative error (RE) by Equation (18) mean absolute error (MAE) by Equation (19) and root means square error (RMSE) by Equation (20).

$$
\begin{gathered}
\text { Error }_{R E}=\frac{\sum_{i=1}^{n}\left(P_{p v i}-P_{p v}\right)}{P_{p v}} * 100 \% \\
\text { Error }_{M A E}=\frac{\sum_{i=1}^{n}\left(P_{p v i}-P_{p v}\right)}{n} \\
\text { Error }_{R M S E}=\sqrt{\frac{\sum_{i=1}^{n}\left(P_{p v i}-P_{p v}\right)^{2}}{n}}
\end{gathered}
$$

where $n$ represents the number of samples, $P p v i$ is power at STC, and $P_{p v}$ is the tracked power.

In Figure 23, the results of the statistical analysis are presented. BMO achieves less relative error, which is an indication of high efficiency. In addition, the effective tracking of GM by BMO causes the RMSE and MAE to be least.

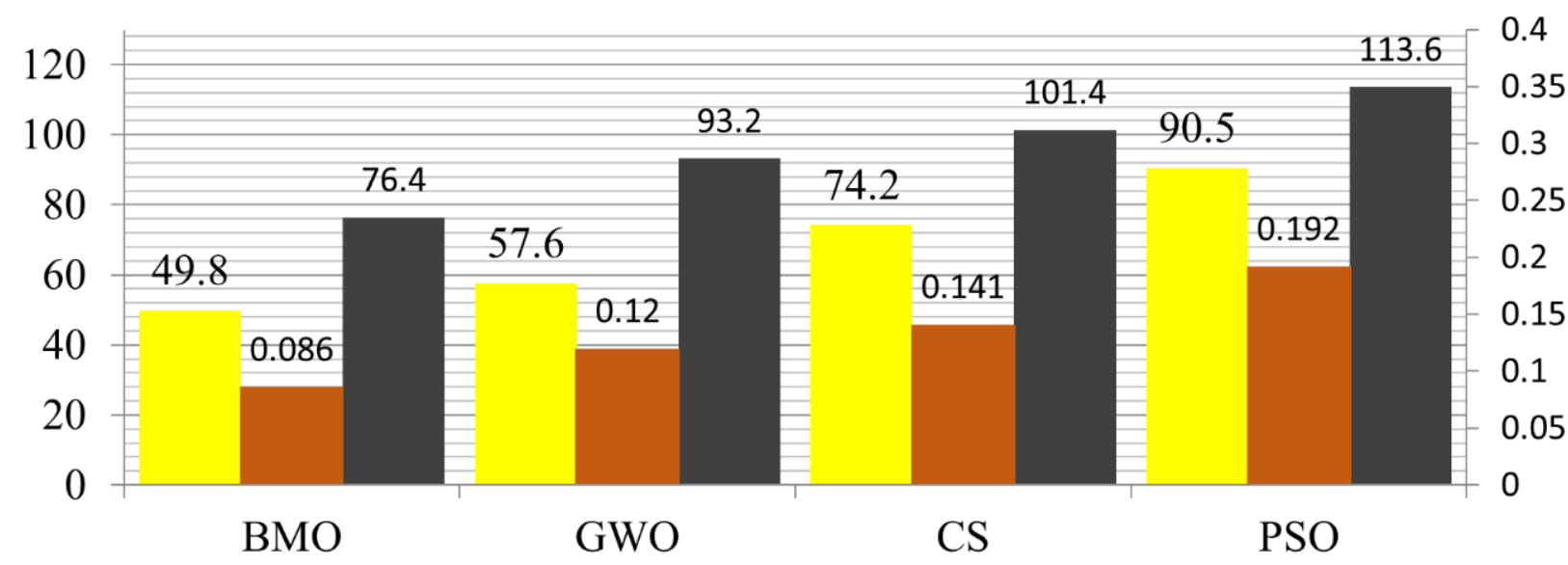

\section{RMSE $\square$ MAE $\square$ RE}

Figure 23. RMSE, MAE, and RE.

\subsection{Efficiency and Performance Evaluation}

Gradient-based MPPT techniques cannot track GM under NTD. The PSO is the leading swarm-intelligence-based technique that has a simpler position updating mechanism based upon the instantaneous velocity vectors of personal best and global best search results. The random numbers rooted in the position updating mechanism and biasing weights slow the convergence time of the PSO search agents. It successfully detects the GM, but the power tracking in the initial dynamic state is lower. CS employs a more complex chaotic search mechanism using the Levy flights. This ensures the maximization of search space exploration, but the larger number of computations adds to the iterative time. Hence, the settling time is worsen under all case studies [40,41,53]. The GWO takes a middle ground and employs multiple decision-making processes. It achieves an early tracking and efficient tracking time, and yet the power efficiency is lower due to the rapid elimination of oscillation preventive measures by leader searching particle. BMOs successfully overcome these hurdles and achieve up to $99.93 \%$ efficiency taking on average $381.1 \mathrm{~ms}$ to track GM showing $53.7 \%$ faster response to that of a standard PSO technique. The proposed technique takes 18-19 iterations to settle at GMPP. BMO achieves 5.6\% higher energy under similar operating conditions of the TEG system. All these factors add to a higher MPPT rating by $\mathrm{BMO}[33,45,54]$. 


\subsection{Hardware Verification}

In this section, the BMO-based MPPT control technique is tested on real-time hardware which used an emulator of TEG whose output power changes with the change in voltages. The change in temperature can be modeled as a change in voltage. The TEG emulator uses a high-wattage resistor as an internal resistor of TEG and a voltage source as a power delivering element. The boost converter is designed to interface the TEG emulator with the load, and the MPPT technique is implemented on low-cost microcontroller, which also validates that the proposed technique can effectively implement on real-time hardware [51]. The hardware setup is presented in Figure 24.

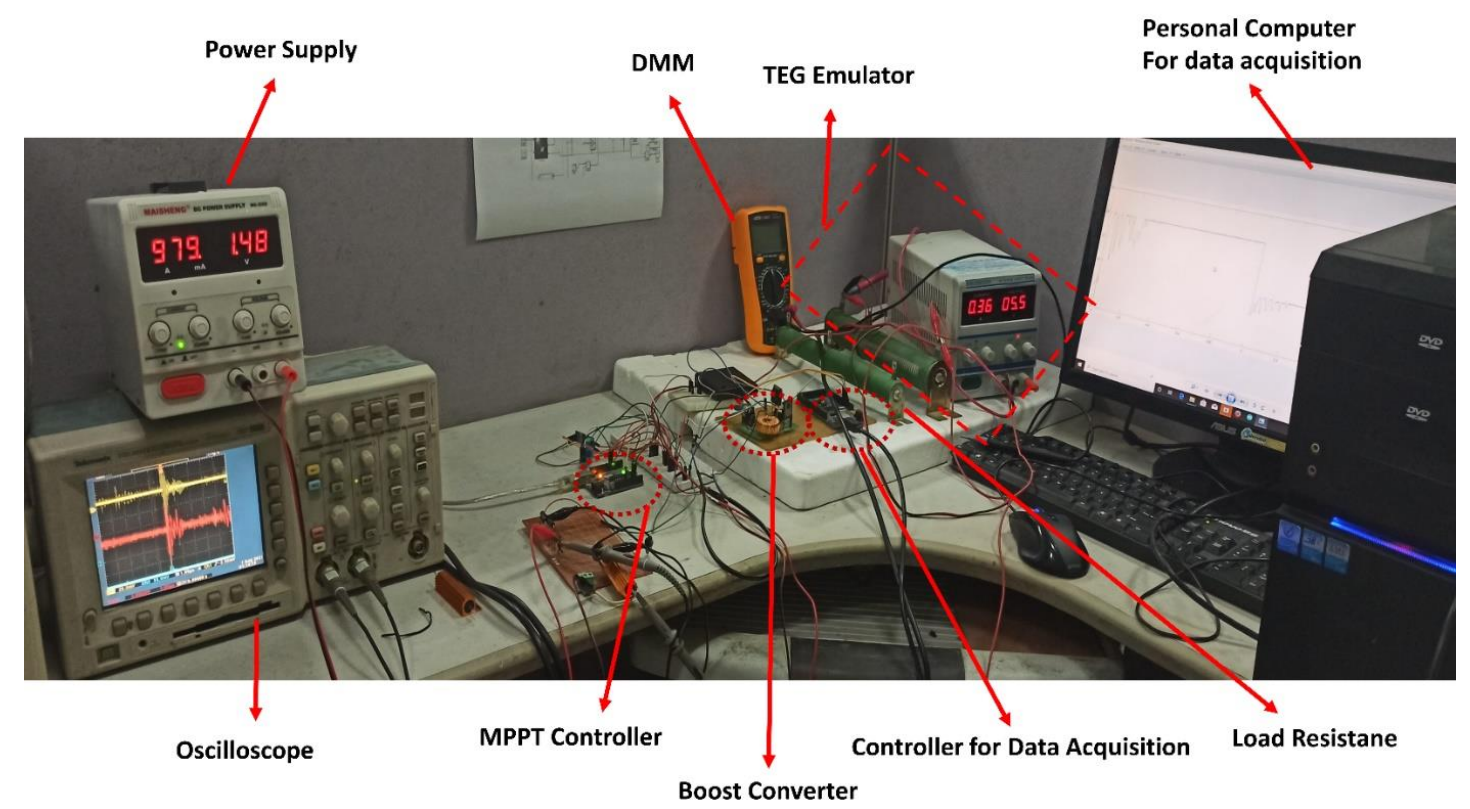

Figure 24. Hardware setup for MPPT control of TEG system.

The results comparison is made between PSO and BMO for the hardware verification. Figure 25a shows the power tracked by the BMO with very low oscillations at the GM at higher power. The time taken to track and settle at GM by BMO is less than $300 \mathrm{~ms}$, and the power tracked is $16.9 \mathrm{~W}$. In comparison to BMO, PSO tracks and settles the GM in $450 \mathrm{~ms}$ with power $16.6 \mathrm{~W}$, which is far less than the power tracked by BMO as shown in Figure $25 \mathrm{~b}$. Thus, the effective performance of BMO MPPT is also validated using low-cost hardware setup.
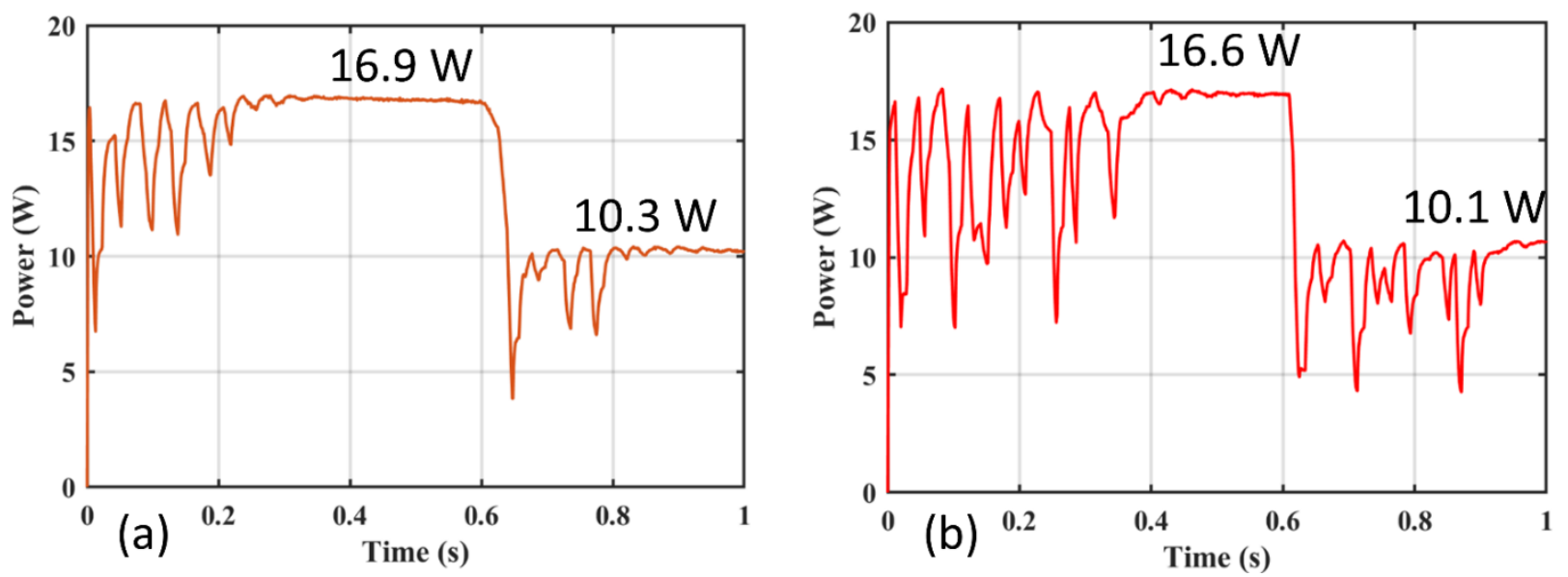

Figure 25. (a) Power tracked by BMO and (b) power tracked by PSO. 


\section{Conclusions}

In this paper, a new MPPT control technique for the centralized TEG system is presented. The BMO is mathematically modeled, and its parameters are studied for MPPT of centralized TEG system. The comparison of BMO is made with highly optimized PSO, GWO, and CS for the nonuniform temperature condition achieving $99.93 \%$ efficiency in tracking power. BMO extracts $5.6 \%$ more energy comparatively. The least oscillations and negligible fluctuations in the output voltage transients provide excellent grid connectivity. The results show that the change in load is managed robustly while delivering a higher magnitude of power during the transitional time. The tracking of GM and settling is performed well within 18 iterations taking $381.1 \mathrm{~ms}$ achieving 53.7\% faster compared to the PSO. BMO ensures negligible fluctuations, high energy yield compared to existing techniques under NUTD. The statistical analysis, quantitative indices, and performance evaluation metrics second the superior performance where BMO outperforms the competing techniques.

Author Contributions: Conceptualization, M.I.T. and A.F.M.; methodology, N.M.K. and A.F.M.; software, N.M.K. and A.F.M.; validation, N.M.K.; formal analysis, N.M.K., M.I.T. and M.H.Z.; investigation, M.H.Z.; resources, A.Z.K., M.A.P.M. and M.H.Z.; data curation, A.F.M.; writing —original draft preparation, M.I.T., M.H.Z. and M.M.; writing—review and editing, M.H.Z., N.M.K. and M.M.; visualization, M.I.T. and M.H.Z.; supervision, M.H.Z., A.Z.K. and M.A.P.M.; project administration, A.Z.K. and M.A.P.M.; funding acquisition, A.Z.K. and M.A.P.M. All authors have read and agreed to the published version of the manuscript.

Funding: This research received no external funding.

Conflicts of Interest: The authors declare no conflict of interest.

\section{References}

1. Karbaschi, H.; Nouri, N.; Rezaei, M.; Rashedi, G. Thermoelectric power generation efficiency of zigzag monolayer nanoribbon of bismuth. Nanotechnology 2020, 31, 375403. [CrossRef]

2. Yuan, C.; Sadashivaiah, G.; Bechtold, T.; Rudnyi, E.B. Efficient Design Optimization of A Thermoelectric Generator by A Combination of Model Order Reduction and Thermal Submodeling Techniques. In Proceedings of the 33rd International ECMS Conference on Modelling and Simulation, ECMS 2019, Caserta, Italy, 11-14 June 2019.

3. Eldesoukey, A.; Hassan, H. 3D model of thermoelectric generator (TEG) case study: Effect of flow regime on the TEG performance. Energy Convers. Manag. 2019, 180, 231-239. [CrossRef]

4. Ballo, A.; Grasso, A.D.; Palumbo, G.; Tanzawa, T. Charge Pumps for Ultra-Low-Power Applications: Analysis, Design and New Solutions. IEEE Trans. Circuits Syst. II Express Briefs 2021, 68, 2895-2901. [CrossRef]

5. Kumar, P.M.; Jagadeesh Babu, V.; Subramanian, A.; Bandla, A.; Thakor, N.; Ramakrishna, S.; Wei, H. The design of a thermoelectric generator and its medical applications. Designs 2019, 3, 22. [CrossRef]

6. Leonov, V.; Torfs, T.; Fiorini, P.; Van Hoof, C. Thermoelectric converters of human warmth for self-powered wireless sensor nodes. IEEE Sens. J. 2007, 7, 650-657. [CrossRef]

7. Zhang, H.; Yue, H.; Huang, J.; Liang, K.; Chen, H. Experimental Studies on a Low Concentrating Photovoltaic/Thermal (LCPV/T) Collector with a Thermoelectric Generator (TEG) Module. Renew. Energy 2021, 171, 1026-1044. [CrossRef]

8. He, M.; Wang, E.; Zhao, C.; Zhang, F. Mathematical Modelling and Heat Transfer Performance of a TEG for Engine Exhaust Heat Recovery. J. Phys. Conf. Ser. 2020, 1624, 032002. [CrossRef]

9. Liang, G.; Zhou, J.; Huang, X. Analytical model of parallel thermoelectric generator. Appl. Energy 2011, 88, 5193-5199. [CrossRef]

10. Pachaivannan, N.; Subburam, R.; Padmanaban, M.; Subramanian, A. Certain investigations of ANFIS assisted CPHO algorithm tuned MPPT controller for PV arrays under partial shading conditions. J. Ambient. Intell. Humaniz. Comput. 2021, 12, 9923-9938. [CrossRef]

11. Jegajothi, B.; Yaashuwanth, C. Generation of maximum power in PV system using EHO based embedded controller. J. Ambient. Intell. Humaniz. Comput. 2021, 12, 5161-5178. [CrossRef]

12. Ballo, A.; Bottaro, M.; Grasso, A.D.; Palumbo, G. Regulated charge pumps: A comparative study by means of verilog-AMS. Electronics 2020, 9, 998. [CrossRef]

13. Rodriguez, A.; Vazquez, A.; Rogina, M.R.; Briz, F. Synchronous boost converter with high efficiency at light load using QSW-ZVS and SiC MOSFETs. IEEE Trans. Ind. Electron. 2017, 65, 386-393. [CrossRef]

14. Lan, S.; Yang, Z.; Stobart, R.; Chen, R. Prediction of the fuel economy potential for a skutterudite thermoelectric generator in light-duty vehicle applications. Appl. Energy 2018, 231, 68-79. [CrossRef]

15. Jaziri, N.; Boughamoura, A.; Müller, J.; Mezghani, B.; Tounsi, F.; Ismail, M. A comprehensive review of Thermoelectric Generators: Technologies and common applications. Energy Rep. 2020, 6, 264-287. [CrossRef] 
16. Motiei, P.; Yaghoubi, M.; GoshtasbiRad, E. Transient simulation of a hybrid photovoltaic-thermoelectric system using a phase change material. Sustain. Energy Technol. Assess. 2019, 34, 200-213. [CrossRef]

17. Ranjan, M.; Maiti, T. Device modeling and performance optimization of thermoelectric generators under isothermal and isoflux heat source condition. J. Power Sources 2020, 480, 228867. [CrossRef]

18. Cai, Y.; Wang, W.-W.; Liu, C.-W.; Ding, W.-T.; Liu, D.; Zhao, F.-Y. Performance evaluation of a thermoelectric ventilation system driven by the concentrated photovoltaic thermoelectric generators for green building operations. Renew. Energy 2020, 147, 1565-1583. [CrossRef]

19. Kumar, V.; Ghosh, S.; Naidu, N.S.; Kamal, S.; Saket, R.; Nagar, S. A current sensor based adaptive step-size MPPT with SEPIC converter for photovoltaic systems. IET Renew. Power Gener. 2021, 15, 1085-1099. [CrossRef]

20. Verma, P.; Garg, R.; Mahajan, P. Asymmetrical interval type-2 fuzzy logic control based MPPT tuning for PV system under partial shading condition. ISA Trans. 2020, 100, 251-263. [CrossRef]

21. Ma, L. Intelligent charging control method of shared vehicle based on MPPT algorithm in the environment of internet of things. $J$. Ambient. Intell. Humaniz. Comput. 2021, 1-9. [CrossRef]

22. Aly, M.; Rezk, H. An improved fuzzy logic control-based MPPT method to enhance the performance of PEM fuel cell system. Neural Comput. Appl. 2021, 1-12. [CrossRef]

23. Hong, C.-M.; Chen, C.-H. Enhanced radial fuzzy wavelet neural network with sliding mode control for a switched reluctance wind turbine distributed generation system. Eng. Optim. 2019, 51, 1133-1151. [CrossRef]

24. Radosavljević, J.; Jevtić, M.; Klimenta, D. Energy and operation management of a microgrid using particle swarm optimization. Eng. Optim. 2016, 48, 811-830. [CrossRef]

25. Zafar, M.H.; Al-shahrani, T.; Khan, N.M.; Feroz Mirza, A.; Mansoor, M.; Qadir, M.U.; Khan, M.I.; Naqvi, R.A. Group teaching optimization algorithm based MPPT control of PV systems under partial shading and complex partial shading. Electronics 2020, 9, 1962. [CrossRef]

26. Mansoor, M.; Mirza, A.F.; Long, F.; Ling, Q. An Intelligent Tunicate Swarm Algorithm Based MPPT Control Strategy for Multiple Configurations of PV Systems Under Partial Shading Conditions. Adv. Theory Simul. 2021, 2100246. [CrossRef]

27. Mansoor, M.; Mirza, A.F.; Duan, S.; Zhu, J.; Yin, B.; Ling, Q. Maximum energy harvesting of centralized thermoelectric power generation systems with non-uniform temperature distribution based on novel equilibrium optimizer. Energy Convers. Manag. 2021, 246, 114694. [CrossRef]

28. Yedala, N.; Kaisare, N.S. Modeling of Thermal Integration of a Catalytic Microcombustor with a Thermoelectric for Power Generation Applications. Energy Fuels 2021, 35, 5141-5152. [CrossRef]

29. Ming, T.; Yang, W.; Huang, X.; Wu, Y.; Li, X.; Liu, J. Analytical and numerical investigation on a new compact thermoelectric generator. Energy Convers. Manag. 2017, 132, 261-271. [CrossRef]

30. Suja, K. Mitigation of power quality issues in smart grid using levy flight based moth flame optimization algorithm. J. Ambient. Intell. Humaniz. Comput. 2021, 12, 9209-9228. [CrossRef]

31. Lee, U.; Park, S.; Lee, I. Robust design optimization (RDO) of thermoelectric generator system using non-dominated sorting genetic algorithm II (NSGA-II). Energy 2020, 196, 117090. [CrossRef]

32. Eltamaly, A.M. A novel particle swarm optimization optimal control parameter determination strategy for maximum power point trackers of partially shaded photovoltaic systems. Eng. Optim. 2021, 1-17. [CrossRef]

33. Mansoor, M.; Mirza, A.F.; Ling, Q. Harris hawk optimization-based MPPT control for PV Systems under Partial Shading Conditions. J. Clean. Prod. 2020, 274, 122857. [CrossRef]

34. Ren, W.; Sun, Y.; Zhao, D.; Aili, A.; Zhang, S.; Shi, C.; Zhang, J.; Geng, H.; Zhang, J.; Zhang, L. High-performance wearable thermoelectric generator with self-healing, recycling, and Lego-like reconfiguring capabilities. Sci. Adv. 2021, 7, eabe0586. [CrossRef]

35. Yang, B.; Zhang, M.; Zhang, X.; Wang, J.; Shu, H.; Li, S.; He, T.; Yang, L.; Yu, T. Fast atom search optimization based MPPT design of centralized thermoelectric generation system under heterogeneous temperature difference. J. Clean. Prod. 2020, $248,119301$. [CrossRef]

36. Yang, B.; Wang, J.; Zhang, X.; Zhang, M.; Shu, H.; Li, S.; He, T.; Yang, L.; Yu, T. MPPT design of centralized thermoelectric generation system using adaptive compass search under non-uniform temperature distribution condition. Energy Convers. Manag. 2019, 199, 111991. [CrossRef]

37. Liu, J.; Zhang, Y.; Zhang, D.; Jiao, S.; Zhang, Z.; Zhou, Z. Model development and performance evaluation of thermoelectric generator with radiative cooling heat sink. Energy Convers. Manag. 2020, 216, 112923. [CrossRef]

38. Aly, M.; Rezk, H. A MPPT based on optimized FLC using manta ray foraging optimization algorithm for thermo-electric generation systems. Int. J. Energy Res. 2021. [CrossRef]

39. Lv, S.; He, W.; Jiang, Q.; Hu, Z.; Liu, X.; Chen, H.; Liu, M. Study of different heat exchange technologies influence on the performance of thermoelectric generators. Energy Convers. Manag. 2018, 156, 167-177. [CrossRef]

40. Zafar, M.H.; Khan, N.M.; Mirza, A.F.; Mansoor, M.; Akhtar, N.; Qadir, M.U.; Khan, N.A.; Moosavi, S.K.R. A novel meta-heuristic optimization algorithm based MPPT control technique for PV systems under complex partial shading condition. Sustain. Energy Technol. Assess. 2021, 47, 101367. 
41. Zafar, M.H.; Khan, N.M.; Mirza, A.F.; Mansoor, M. Bio-inspired optimization algorithms based maximum power point tracking technique for photovoltaic systems under partial shading and complex partial shading conditions. J. Clean. Prod. 2021, 309, 127279. [CrossRef]

42. Kanimba, E.; Pearson, M.; Sharp, J.; Stokes, D.; Priya, S.; Tian, Z. A comprehensive model of a lead telluride thermoelectric generator. Energy 2018, 142, 813-821. [CrossRef]

43. Mirza, A.F.; Mansoor, M.; Zhan, K.; Ling, Q. High-efficiency swarm intelligent maximum power point tracking control techniques for varying temperature and irradiance. Energy 2021, 228, 120602. [CrossRef]

44. Kumar, S.; Heister, S.D.; Xu, X.; Salvador, J.R.; Meisner, G.P. Thermoelectric generators for automotive waste heat recovery systems part I: Numerical modeling and baseline model analysis. J. Electron. Mater. 2013, 42, 665-674. [CrossRef]

45. Mirza, A.F.; Mansoor, M.; Ling, Q.; Yin, B.Q.; Javed, M.Y. A Salp-Swarm Optimization based MPPT technique for harvesting maximum energy from PV systems under partial shading conditions. Energy Convers. Manag. 2020, 209, 112625. [CrossRef]

46. Mirza, A.F.; Mansoor, M.; Ling, Q. A novel MPPT technique based on Henry gas solubility optimization. Energy Convers. Manag. 2020, 225, 113409. [CrossRef]

47. Mamur, H.; Coban, Y. Detailed modeling of a thermoelectric generator for maximum power point tracking. Turk. J. Electr. Eng. Comput. Sci. 2020, 28, 124-139. [CrossRef]

48. Zheng, Y.; Zhang, Q.; Jin, W.; Jing, Y.; Chen, X.; Han, X.; Bao, Q.; Liu, Y.; Wang, X.; Wang, S. Carbon nanotube yarn based thermoelectric textiles for harvesting thermal energy and powering electronics. J. Mater. Chem. A 2020, 8, 2984-2994. [CrossRef]

49. Yang, B.; Zhu, T.J.; Wang, J.B.; Shu, H.C.; Yu, T.; Zhang, X.S.; Yao, W.; Sun, L.M. Comprehensive overview of maximum power point tracking algorithms of PV systems under partial shading condition. J. Clean. Prod. 2020, 268, 121983. [CrossRef]

50. Yadav, K.; Kumar, B.; Swaroop, D. Mitigation of mismatch power losses of PV array under partial shading condition using novel odd even configuration. Energy Rep. 2020, 6, 427-437. [CrossRef]

51. Mirza, A.F.; Mansoor, M.; Zerbakht, K.; Javed, M.Y.; Zafar, M.H.; Khan, N.M. High-efficiency hybrid PV-TEG system with intelligent control to harvest maximum energy under various non-static operating conditions. J. Clean. Prod. 2021, $320,128643$. [CrossRef]

52. Khan, N.M.; Khan, U.A.; Zafar, M.H. Maximum Power Point Tracking of PV System under Uniform Irradiance and Partial Shading Conditions using Machine Learning Algorithm Trained by Sailfish Optimizer. In Proceedings of the 2021 th International Conference on Energy Conservation and Efficiency (ICECE), Lahore, Pakistan, 16-17 March 2021; pp. 1-6.

53. Zafar, M.H.; Khan, U.A.; Khan, N.M. Hybrid Grey Wolf Optimizer Sine Cosine Algorithm based Maximum Power Point Tracking Control of PV Systems under Uniform Irradiance and Partial Shading Condition. In Proceedings of the 2021 4th International Conference on Energy Conservation and Efficiency (ICECE), Lahore, Pakistan, 16-17 March 2021; pp. 1-6.

54. Mirza, A.F.; Ling, Q.; Javed, M.Y.; Mansoor, M. Novel MPPT techniques for photovoltaic systems under uniform irradiance and Partial shading. Sol. Energy 2019, 184, 628-648. [CrossRef] 